\title{
LA CONSTRUCCIÓN DEL \\ MILAGRO MEXICANO: \\ EL INSTITUTO MEXICANO DE \\ INVESTIGACIONES TECNOLÓGICAS, EL BANCO DE MÉXICO Y LA ARMOUR \\ RESEARCH FOUNDATION
}

\author{
Aurora Gómez-Galvarriato \\ El Colegio de México
}

\begin{abstract}
Es fácil decir que "la tecnología es la llave para la industrialización". En realidad, la puerta a la industrialización se abre como la de las cajas de seguridad de un banco, excepto que existen varias cerraduras en lugar de sólo dos. La tecnología es una de las llaves. Todas las llaves deben ser giradas simultáneamente para que la puerta se abra. Si decidimos no preocuparnos por alguna de las otras llaves, no servirá de nada girar la llave de la tecnología con más fuerza, pues de todas formas la puerta permanecerá cerrada.

Armour Research Foundation, Technological Audit of Selected Mexican Industries, p. 1.
\end{abstract}

\section{INTRODUCCIÓN}

Gl "milagro mexicano", esas tres décadas que corrieron de

-1940 a 1970, en las que el país se transformó creciendo a tasas anuales por encima del $5 \%$, ha sido analizado, sobre todo,

Fecha de recepción: 15 de enero de 2019

Fecha de aceptación: 19 de junio de 2019 
a partir de sus grandes variables macroeconómicas. Debido a las crisis recurrentes que golpearon al país a partir de los años setenta, su análisis ha puesto énfasis en sus debilidades, resaltando los problemas que generó un excesivo proteccionismo. ${ }^{1}$ Al estudiar el éxito económico alcanzado por varios países asiáticos como Japón, Corea del Sur o China, se ha destacado el importante papel que desempeñó el Estado en el desarrollo de capacidades tecnológicas. ${ }^{2}$ En México el gobierno también llevó a cabo políticas enfocadas a promover el desarrollo y adaptación de nuevas tecnologías que explican en alguna medida el éxito alcanzado durante el "milagro mexicano". Sin embargo, éstas han sido escasamente estudiadas.

Uno de los esfuerzos más destacados fue el programa de investigación agrícola que iniciaron en 1943 la Secretaría de Agricultura y Fomento y la Fundación Rockefeller para el desarrollo de híbridos de maíz y de trigo de alto rendimiento en variedades resistentes a las plagas, así como para el mejoramiento genético del frijol, el arroz y otros cultivos. Como resultado de estos esfuerzos, entre 1940 y 1960 el rendimiento medio del maíz por hectárea aumentó $34 \%$, mientras que el del trigo ascendió $76 \%{ }^{3}$ Los frutos de estas investigaciones tuvieron trascendencia más allá del ámbito nacional al iniciar la llamada revolución verde. Diversos estudios han abordado este proceso, si bien aún hace

\footnotetext{
1 Véanse, por ejemplo, Reynolds, "Por qué el 'desarrollo establilizador", Solís, La realidad económica, pp. 169-204; CÁRdENAS, La política económica, pp. 23-85; CÁrdenAs, "La economía mexicana”, pp. 503-521; MORENO-BRID y Ros Bosch, Desarrollo y crecimiento, pp. 132-169.

2 Véanse Johnson, MITI and the Japanese Miracle; Oкімото, Between MITI and the Market: Japanese Industrial Policy; WANG, "From technological catch-up"; PACK y WestPhal, "Industrial strategy and technological"; ViotTI, "National Learning Systems".

${ }^{3}$ Myren, "The Rockefeller Foundation Program", p. 1; Urquidi y Lajous, Educación Superior, p. 62.
} 
falta explorar más ampliamente sus consecuencias en el desarrollo económico del país durante dicho periodo. ${ }^{4}$

En cambio, se ha puesto escasa atención en un proyecto paralelo que emprendió el gobierno mexicano en relación con el sector industrial, que fue el motor del desarrollo económico durante dicho periodo. Este trabajo busca subsanar este déficit al explorar la estrategia que siguió el gobierno mexicano para construir las capacidades tecnológicas que requería el desarrollo industrial del país. Estudia el papel central que desempeñó en este proceso el Banco de México, cuyos directivos supieron aprovechar la coyuntura económica y política que generó la segunda guerra mundial, para atraer al país la experiencia en materia de desarrollo tecnológico que venía acumulándose en Estados Unidos. A diferencia de lo que suele destacarse del periodo, esta no fue una historia de aislacionismo, sino de cooperación internacional, en la que la visión de algunos funcionarios públicos se conjuntó con la de varios ingenieros y científicos estadounidenses y mexicanos para crear una institución clave para el desarrollo tecnológico del país: el Instituto Mexicano de Investigaciones Tecnológicas (IMIT). A lo largo de estas páginas se estudia la creación y evolución del Instituto, así como sus principales contribuciones al desarrollo industrial del país.

\section{EL INICIO}

Durante la década de 1940 fue consolidándose en el gobierno de México un grupo de ingenieros, abogados y economistas que consideraban que la participación gubernamental en el fomento industrial era un factor esencial para lograr el desarrollo económico del país. Muchos de los miembros de este grupo pertenecieron a una generación llamada epirrevolucionaria

\footnotetext{
${ }^{4}$ Véanse, por ejemplo, Grifrin, Economía política del cambio agrario; SonNENFELD, "Mexico’s ‘Green Revolution”.
} 
o constructora por el historiador Luis González, la cual tuvo un destacado papel en la conducción del país por más de medio siglo. ${ }^{5}$ A este grupo pertenecieron personajes como Eduardo Villaseñor, Gonzalo Robles, Eduardo Suárez, Ramón Beteta, Daniel Cosío Villegas y Víctor Urquidi, entre otros, quienes ocuparon distintos cargos en la Secretaría de Hacienda, la Secretaría de la Economía Nacional y el Banco de México. Eran parte de una generación de intelectuales que maduró durante la “era de la racionalización” de la posguerra, en la que los economistas e industrialistas se enfocaron en desarrollar planes de largo alcance para alcanzar el crecimiento industrial nacional, inspirados por las ideas alemanas sobre la racionalización industrial. ${ }^{6}$ Anticipándose a las ideas que Gerschenkron desarrollaría algunos años después, consideraban que era importante que el Estado sustituyera aquellos factores de la producción que la iniciativa privada no estaba aportando, a modo de compensar las desventajas que enfrentaba el desarrollo industrial con relación a los países desarrollados. ${ }^{7}$ En ese tenor, Gonzalo Robles señalaba, "los países nuevos o subdesarrollados han llegado finalmente a la conclusión de que para alcanzar las metas deseadas, ponderando factores y recursos, no se puede confiar en la acción de fuerzas ciegas, que algunos suponen naturales como la gravitación, cuando en realidad están profundamente institucionalizadas". ${ }^{8}$ Para lograr el desarrollo económico consideraba necesaria una programación que permitiera adjudicar los recursos en la forma más eficiente, en la que el Estado, junto con la iniciativa privada, debía desempeñar un papel muy importante, entre otras medidas, contribuyendo a la orientación y coordinación general del proceso y promoviendo las

${ }^{5}$ González, Historia de la Revolución Mexicana, pp. 143-183.

${ }^{6}$ Gauss, Made in Mexico, p. 111.

7 Gauss, Made in Mexico, p. 116-117; Gerschenkron, Economic Backwardness.

8 Robles, "El desarrollo industrial”, p. 168. 
instituciones rectoras de educación, investigación y fomento, para facilitar la empresa. ${ }^{9}$

Gracias a su iniciativa, a lo largo de la década de 1940, el Banco de México, Nacional Financiera (Nafinsa) y el Banco de Comercio Exterior (Bancomext), tres instituciones relativamente jóvenes, creadas en 1925, 1934 y 1937, respectivamente, fueron involucrándose cada vez más en apoyar técnica y financieramente el desarrollo industrial. En 1940, una nueva ley orgánica transformó a Nafinsa, al definirla como banca de fomento y otorgarle facultades para promover, crear y auxiliar financieramente a empresas prioritarias. Al mismo tiempo, se le dotó de los medios necesarios para promover la inversión de grandes capitales en obras de infraestructura e industria básica. ${ }^{10}$ El Banomext, que fue creado originalmente para promover, desarrollar y organizar el comercio exterior, hacia la década de 1940 fue incrementando su instrumental de política para operar fideicomisos por cuenta del Gobierno federal, mediante los cuales creó empresas para el manejo de los principales productos de exportación y sustituir las importaciones que requería la producción agrícola de exportación. ${ }^{11}$

Por su parte, en 1941 el Banco de México creó, a sugerencia de la Convención de Banqueros reunida en Acapulco ese año, la Oficina de Investigaciones Industriales, con el objeto de "cooperar con otras instituciones y llenar transitoria o permanentemente lagunas institucionales o funcionales” con el fin de procurar "nuevos y eficaces medios y aparatos de promoción y apoyo para los programas de industrialización”. ${ }^{12} \mathrm{Su}$ primer director fue Gonzalo Robles, quien había sido director general del banco de 1935 a 1941. Su objetivo fue realizar investigaciones que permitieran orientar mejor los recursos financieros que el

\footnotetext{
9 Robles, "El desarrollo industrial”, p. 169.

${ }^{10}$ Campos Salas, "Las instituciones nacionales de crédito", p. 431.

11 Campos Salas, "Las instituciones nacionales de crédito", pp. 433-434.

12 Robles, “El desarrollo industrial”, p. 191.
} 
banco estaba aportando a la industria. ${ }^{13}$ Para lograrlo financió la investigación de varios problemas que consideró de especial importancia por medio de empresas de consultoría en ingeniería en Nueva York, como la Ford, la Bacon y Davis y la Higgins Industries Inc. ${ }^{14}$ De acuerdo con Eduardo Villaseñor, era importante para el país contar con proyectos completos de investigación industrial, antes de involucrarse en su ejecución, con el fin de evitar errores como el apoyar industrias que resultaran obsoletas al poco tiempo de haber sido establecidas. ${ }^{15}$ Asimismo, la Oficina de Investigaciones Industriales desempeñó un importante papel en la administración de las leyes protectoras de la industria que comenzaron a emitirse a partir de 1941 al realizar los estudios técnico-económicos de las solicitudes de protección y la labor posterior de inspección técnica. ${ }^{16}$ Esta oficina se convirtió en 1943 en el Departamento de Investigaciones Industriales.

Hacia 1944, cuando la segunda guerra mundial aún no terminaba, era claro para el Departamento de Investigaciones Industriales del Banco de México que existía en el país un profundo desconocimiento de sus potencialidades de desarrollo industrial mediante la aplicación de mejores tecnologías. El Banco de México, con la iniciativa de su director general, Eduardo Villaseñor, y su asesor técnico, Gonzalo Robles, comisionó a la Armour Research Foundation (ARF) del Illinois Institute of Technology para hacer un estudio sobre la situación tecnológica de los principales sectores de la actividad industrial de México, con el objeto de aumentar sus niveles tecnológicos y encontrar formas para aplicar para su desarrollo la investigación y el control científicos.

13 Turrent, Banco de México, p. 43.

14 Gauss, Made in Mexico, p. 127.

15 Intervención de Eduardo Villaseñor en la conferencia "Discussion by Mexican Guests", en Armour Research Foundation, Proceedings, p. 157. 16 Robles, "El desarrollo industrial”, p. 191. 
Esta iniciativa se apoyó en la experiencia de Argentina, en donde en 1942, a instancias de Raúl Prebisch, entonces gerente del Banco Central de la República Argentina, y de Carlos Acebedo, ministro de Hacienda, la Corporación para la Promoción del Intercambio ${ }^{17}$ contrató a la ARF para realizar un amplio estudio sobre las posibilidades industriales y agrícolas del país, que entregó en agosto de 1943. ${ }^{18}$ Probablemente Raúl Prebisch habló de este tema cuando visitó México en 1944 y dictó varias conferencias en el Banco de México y en El Colegio de México. ${ }^{19}$ Poco después, Eduardo Villaseñor consultó a los señores Harold Vagtborg, presidente del Midwest Research Institute en Kansas y anterior director del ARF, y a Maurice Holland, asesor de investigación industrial, de Nueva York, quienes lo visitaron en México, en relación con contratar a la ARF para realizar un estudio similar para México. ${ }^{20}$

\section{LA ARMOUR RESEARCH FOUNDATION EN MÉXICO:} SUS PRIMEROS ESTUDIOS

La ARF, localizada en Chicago, Illinois, y afiliada al Instituto Tecnológico de Illinois, se funda en 1934 como una corporación sin fines de lucro, para ofrecer servicios de investigación y de ingeniería experimental a la industria. La ARF era entonces uno

17 "Una organización privada constituida con el propósito de estimular el comercio con Estados Unidos y otros países de la región, así como estudiar la manera de perfeccionar procesos industriales, aprovechar de mejor manera las materias primas existentes y promover la instalación de industrias nuevas." Rougier y Odisio, Argentina será industrial, p. 136. Mediante un decreto gubernamental, en 1941 el gobierno dotó a la Corporación para la Promoción del Intercambio de fondos para estimular las actividades tecnológicas y emprender medidas que mejoraran el intercambio.

18 Armour Research Foundation, Technological and Economic Survey of Argentine Industries.

19 Gauss, Made in Mexico, p. 115.

20 Armour Research Foundation, Proceedings, p. 3. 
de los dos más grandes institutos de investigación industrial en Estados Unidos. La organización contaba hacia 1942 con un personal de 265 especialistas en prácticamente todos los campos de la ciencia y la tecnología. ${ }^{21} \mathrm{Su}$ investigación se enfocaba a la mecánica aplicada, la cerámica y minerales, la química y la ingeniería química, la ingeniería eléctrica y la física. ${ }^{22}$ Para dimensionar la importancia de los institutos de investigación industrial como oferentes de servicios técnicos para la industria estadounidense, es importante señalar que hacia 1950 existían en Estados Unidos 2845 laboratorios de investigación industrial, a los que se sumaban 41 laboratorios gubernamentales, así como 281 universidades que ofrecían servicios de investigación a la industria. ${ }^{23}$

Los trabajos de investigación de la ARF iniciaron en México en noviembre de 1944, con el fin de servir como "apoyo a un programa ordenado de industrialización en ciertos campos de la economía mexicana, y promover el desarrollo de la tecnología industrial en México". ${ }^{24}$ El Banco de México solicitó a la ARF llevar a cabo una auditoría tecnológica de algunos sectores que consideraron de especial importancia para el desarrollo nacional: el de combustibles sólidos, el de cueros y pieles, el de fibras y el de productos forestales, sobre los que se estudiarían tanto las industrias relacionadas como las actividades asociadas, en la agricultura, la educación técnica y la investigación. ${ }^{25}$

Los objetivos planteados fueron: examinar y evaluar el estado tecnológico de estas industrias y sus operaciones relacionadas, descubrir formas específicas para ayudar a estas industrias con

\footnotetext{
21 Armour Research Foundation, Technological and Economic Survey of Argentine Industries, p. xi.

22 RAND, Industrial Research, p. 28.

${ }^{23}$ Información tomada de la lista de laboratorios reportada en RAND, Industrial Research.

${ }^{24}$ Armour Research Foundation, Technological Audit, p. vii.

25 Armour Research Foundation, Technological Audit, p. vii.
} 
la aplicación de tecnología industrial moderna, y proponer métodos para hacer esta tecnología disponible; proponer nuevas industrias, adicionales a las existentes, que pudieran ser establecidas en estos sectores y descubrir formas específicas en que la investigación científica pudiera aplicarse para solucionar los problemas que representaran barreras al desarrollo industrial mexicano o un peligro para que los mercados continuaran optando por los productos mexicanos. ${ }^{26}$

Con el fin de llevar a cabo el proyecto, la ARF estableció una oficina en la Ciudad de México dirigida por el doctor Francis W. Godwin como director asociado y director residente en México, quien había fungido hasta entonces como director de la división internacional de la fundación. La ARF envió a México un equipo técnico permanente al que se sumó un equipo mexicano, tanto técnico como no técnico, que proporcionó el Banco de México. Este equipo fue apoyado por algunos especialistas que viajaron a México por periodos cortos o apoyaron las investigaciones desde Chicago. ${ }^{27} \mathrm{~L}$ a investigación comprendió la organización de datos básicos y la realización de entrevistas e inspecciones en diversas regiones del país relacionadas con los temas del estudio. Debido a que a muchos sitios era imposible llegar por carretera, viajaron a ellos en avionetas y, a otros más inaccesibles, incluso llegaron a caballo. ${ }^{28}$

El director del proyecto, Francis W. Godwin, expresaba que con la cooperación del Banco de México fue posible traducir las observaciones de campo en investigaciones de laboratorio concretas que se llevaron a cabo tanto en Estados Unidos como en

\footnotetext{
26 Armour Research Foundation, Technological Audit, p. vii.

27 Armour Research Foundation, Technological Audit, p. vii; "Industrial Research Progress at Armour Research Foundation 1944-1945", en Chemical and Engineering Nerws, American Chemical Society, 24 (25 ene. 1946), p. 161, reimpreso con adiciones en ARMOUR Research Foundation, Technological Audit, pp. 189-208.

28 Armour Research Foundation, Technological Audit, pp. vii-viii.
} 
México. El proyecto buscó no sólo producir el estudio contratado sino ir construyendo capacidades técnicas en el país. Para lograrlo, señalaba: "Hemos tratado de ayudar crecientemente en el intercambio -de doble vía- del personal técnico", para lo que procuraron que hubieran "de una a tres veces tantos técnicos mexicanos estudiando en nuestros laboratorios de la Fundación, como había técnicos norteamericanos haciendo las investigaciones en México". ${ }^{29}$

Con este propósito, a lo largo de 1945, el Banco de México abrió 30 nuevas becas enfocadas a apoyar a estudiantes a realizar estudios avanzados en una especialidad técnica o económica en una universidad extranjera u operación industrial. La ARF colaboró con el Banco para seleccionar a los candidatos y ayudarles a elegir la mejor institución de acuerdo con su especialidad, apoyando su admisión a la misma. Un número considerable de ellos fueron llevados primero a los laboratorios de la ARF para entrenamiento práctico en operaciones de laboratorio específicas antes de entrar a las universidades en las que cursaron sus estudios. Adicionalmente, la ARF abrió tres becas, con duración de tres años, que fueron otorgadas a estudiantes mexicanos con estudios en ciencias o ingenierías. ${ }^{30}$

\section{LA CONFERENCIA MEXICANO-AMERICANA EN INVESTIGACIÓN INDUSTRIAL}

Al elaborar el estudio sobre la potencialidad de varias industrias mexicanas que podrían beneficiarse con la adopción de nuevas tecnologías y las dificultades que esto conllevaba, la ARF recomendó que se estableciera en México un instituto de investigaciones industriales. Debido a que este proyecto requería sumar una serie de voluntades, tanto en el ámbito gubernamental

29 Armour Research Foundation, Proceedings, p. 4.

30 Armour Research Foundation, Technological Audit, p. viii. 
como entre los principales financieros e industriales del país, decidieron organizar una conferencia en la que se sensibilizara a los directivos y ejecutivos del más alto nivel de las instituciones gubernamentales, educativas, industriales y financieras del país, sobre la importancia que tenía la investigación industrial para impulsar el desarrollo en México. ${ }^{31}$

Cuando el director de la ARF, J. E. Hobson, visitó la Ciudad de México en 1944, se convenció de la relevancia de realizar esta conferencia y pidió su apoyo a Frank A. Hecht, director de la Asociación de Comercio de Chicago y fideicomisario del Illinois Institute of Technology y la ARF. Para reunir los fondos necesarios, Hecht formó el Comité de la Organización de la Conferencia, al que se sumaron los presidentes de compañías importantes de Chicago como Continental Illinois National Bank and Trust, International Harvester, Sears Roebuck, Pullman, Quaker Oats y el National City Bank de Nueva York, entre otras. ${ }^{32}$

Con el apoyo financiero de estas empresas, la ARF organizó la Conferencia Mexicano-Americana en Investigación Industrial que tuvo lugar del 30 de septiembre al 6 de octubre de 1945 en la ciudad de Chicago, apenas unas semanas después de que hubiera terminado la segunda guerra mundial. Esta conferencia, que fue la primera que se llevó a cabo en el campo de la investigación industrial entre dos naciones, tenía como propósito reunir a líderes en cuestiones industriales y educativas de ambos países para generar discusiones mutuamente benéficas, mostrándoles "la investigación en acción". ${ }^{33}$

A la cabeza de la comitiva mexicana estaban Gustavo P. Serrano, secretario de Economía y, Eduardo Villaseñor, director

31 Armour Research Foundation, Technological Audit, p. viii.

32 Armour Research Foundation, Proceedings, p. 4.

33 Armour Research Foundation, Proceedings, p. xiii. 
general del Banco de México. ${ }^{34}$ La delegación mexicana fue conformada por 36 personas, entre quienes estaban varios directores y presidentes de las principales empresas mexicanas, tanto del sector industrial como del financiero, así como los responsables de los principales centros de investigación científica del país (véase la tabla 1). Los delegados volaron junto con sus esposas en aviones contratados a Aerovías Braniff, ${ }^{35}$ la que tenía una conexión de largo aliento con México pues su dueño, Thomas Braniff, estaba vinculado con una familia que había hecho una importante fortuna en México antes de la revolución mexicana. $\mathrm{Su}$ esposa fungió como anfitriona no oficial de las esposas de los delegados. ${ }^{36}$

El ambiente que prevalecía al final de la segunda guerra mundial es fundamental para explicar el contexto en el que esta conferencia se llevó a cabo. Durante la ceremonia de inauguración de la conferencia, el presidente del Instituto Tecnológico de Illinois, Dr. Henry T. Heald se refirió a la política de "buenos vecinos" que el presidente de Estados Unidos, Franklin D. Roosevelt, había señalado seguiría su país hacia América Latina, ${ }^{37}$ indicando que la reunión que estaban por emprender significaba hacer de esta frase una realidad..$^{38}$ Por su parte, en su

34 "Mexican-American Conference" (7 de noviembre de 1945), Illinois Institute of Technology News Bureau, News Releases, oct.-dic., 1945, Digitalizado por the Internet Archive http://www.archive.org/details/newspreleaseoctdec1945illi (consultado el 7 de octubre de 2018).

${ }_{35}$ Paul D. Hermann, "Mexican-American Conference on Industrial Research", en Armour Research Foundation, Technological Audit, pp. 185-186.

36 "Mexican Society" (5 de octubre de 1945), llinois Institute of Technology News Bureau, News Releases, oct.-dic. 1945. Digitalizado por the Internet Archive http://www.archive.org/details/newspreleaseoctdec1945illi.

37 El uso de este término fue usado por primera vez por Franklin D. Roosevelt en 1933 en el marco de la VII Conferencia Panamericana.

${ }^{38}$ Discurso del Dr. H. T. Heald en la inauguración de la Conferencia Mexicano-Americana en Investigación Industrial, en Armour RESEARCH FoundATION, Proceedings, p. 2. 
discurso inaugural, el Ing. Gustavo Serrano expresó que habían aceptado la invitación:

[...] no sólo porque queríamos aprender muchas cosas nuevas, y aprovechar esta oportunidad para usar el conocimiento científico que podemos obtener aquí, pero, sobre todo, para expresarle a la gente de Chicago y de los Estados Unidos, todo lo que profundamente apreciamos la amistad que existe entre los dos países y cómo esperamos que nuestra amistad continúe. Hemos sido aliados, y seguiremos siendo amigos en tiempos de paz para nuestro beneficio mutuo. $^{39}$

Serrano explicó que México estaba comenzando a industrializarse y que este proceso debía sentar sus bases: primero, en la investigación científica y los laboratorios; segundo, en la electrificación del país; y tercero, en la modernización de su maquinaria y de la industria en general, especialmente en aquella que pudieran transformar las materias primas del país para satisfacer las crecientes demandas del pueblo de México. "Nuestro objetivo y deseo es aumentar los muy bajos niveles de vida de las clases bajas de México", ${ }^{40}$ afirmó, lo que requería de maquinaria y equipo eficiente, que hacía mucho tiempo que venía necesitándose. Un objetivo que él consideraba era del interés también de los estadounidenses. "Lograr aumentar el nivel de vida del pueblo de México", señalaba, "no sólo beneficiará a las clases más necesitadas y a México en general, sino también será para el beneficio de América y la humanidad". ${ }^{41}$

39 Armour Research Foundation, Proceedings, p. 5.

40 Armour Research Foundation, Proceedings, p. 5.

41 Armour Research Foundation, Proceedings, p. 6. 


\section{Tabla 1 \\ INVITADOS DE MÉXICO A LA CONFERENCIA MEXICANO- AMERICANA EN INVESTIGACIÓN INDUSTRIAL}

\section{Gobierno}

Lic. Eduardo Suárez*

Secretario de la Secretaría de Hacienda y

Crédito Público

Presidente del Consejo de Administración

Petróleos Mexicanos

Presidente de la Junta de Administración y

Vigilancia de Ferrocarriles Nacionales de

México

Ing. Gustavo P. Serrano

Sr. Eduardo Villaseñor

Ing. Gonzalo Robles

Sr. Enrique Sarro

Ing. Enrique Lerch Gómez

Ing. Carlos Ramírez Ulloa

Dr. Ignacio Aguerrebere

Ing. Manuel Torres Torrija
Secretario de la Secretaría de la Economía Nacional

Expresidente de la Cámara Minera

Director General del Banco de México

Presidente de la Comisión Mexicana de

Fomento Interamericano

Comité Asesor de Nacional Financiera y

Asociación Hipotecaria Mexicana

Jefe del Departamento de Investigaciones

Industriales del Banco de México

Exdirector del Banco de México

Presidente del Consejo de Dirección de

Altos Hornos

Subdirector de Nacional Financiera

Jefe de la Sección Electromecánica de

Comisión Federal de Electricidad

Vocal ejecutivo de la Comisión Federal de

Electricidad

Director general de Normas de la

Secretaría de Economía Nacional

Subdirector de Normas de la Secretaría de la Economía Nacional

Notas: * Si bien Eduardo Suárez aparece en la lista de invitados, es probable que no haya asistido pues no aparece ninguna intervención suya en la conferencia. Es probable que haya asistido Roberto Garza en lugar de Rómulo Garza, pues es de este último de quien se hace mención en los reportajes del acto.

Fuente: Armour Research Foundation, Proceedings, pp. ix-x. 
Tabla 1 (continúa)

\section{Industria}

Sr. Rómulo Garza/ Sr. Roberto Director general de Vidriera de Monterrey Garza*

Sr. Prisciliano Miguel Elizondo Director de Fundidora de Fierro y Acero

Lic. Pablo Macedo de Monterrey

Sr. Tom E. Braniff
Ing. Bernardo Quintana
Arrioja

Delegado del Consejo de Administración y director ejecutivo de Sosa-Texcoco, y Carburo

Director de la Sociedad Mexicana de Crédito Industrial

Presidente del Consejo de Administración de la Compañía Minera La Favorita y Anexas

Presidente de Braniff Airways y Aerovías Braniff

Representante de la Cámara de la Industria Curtidora: United Shoe and Leather Company

Sr. Sealtiel L. Alatriste

Auditor de la fábrica de cemento La Cruz Azul

Expresidente de la Cámara de Comercio de México en Nueva York

Sr. José Cruz y Celis

Presidente de la Confederación de

Cámaras Industriales Presidente de

Productos de Maíz

Ing. Luis Flores Arias

Presidente de Construcciones Concreto

Sr. Guillermo Magaña Galván

Sr. Miguel Guzmán

Productora Mexicana

Sr. Alejandro Noye

Cadena Productora Mexicana

Presidente de la Confederación de

Cámaras Nacionales de Comercio

Consejero del Banco de México y

La Azteca

Sr. Lee González

Representante de Aerovías Braniff

Sr. Antonio Ruiz Galindo Jr. Vicegerente de Distribuidora Mexicana

Notas: * Si bien Eduardo Suárez aparece en la lista de invitados, es probable que no haya asistido pues no aparece ninguna intervención suya en la conferencia. Es probable que haya asistido Roberto Garza en lugar de Rómulo Garza, pues es de este último de quien se hace mención en los reportajes del acto.

Fuente: Armour Research Foundation, Proceedings, pp. ix-x. 
Tabla 1 (continúa)

INVITADOS DE MÉXICO A LA CONFERENCIA MEXICANOAMERICANA DE INVERSIÓN INDUSTRIAL

\section{Instituciones financieras}

Sr. Luis Legorreta

Sr. Salvador Ugarte

Sr. Luis Montes de Oca

Sr. Franz Mayer

Sr. Virgilio Garza

Sr. William B. Richardson

Sr. Carlos Trouyet

Lic. Gustavo Velasco

Ing. Valentín Escobar
Director general del Banco Nacional de México

Director general del Banco de Comercio

Presidente del Banco Internacional

Exsecretario de Hacienda y Crédito

Público

Exdirector general del Banco de México

Presidente de Inversiones Bursátiles

Presidente del Consejo de Administración de Crédito Industrial de Monterrey

Gerente del National City Bank de Nueva York en México

Banquero de Inversiones Industriales

Expresidente de la Bolsa de Valores de

México

Abogado consultor del Banco

Internacional

Secretario del Consejo de Aseguradora

Mexicana

Jefe del departamento de Investigación

y Desarrollo de la Sociedad Mexicana de

Crédito Industrial

\section{Instituciones educativas y de investigación}

Dr. Nabor Carrillo

Jefe del Departamento de Investigaciones

Científicas, UNAM

Jefe de Investigadores de la Comisión

Impulsora y Coordinadora de

Investigación Científica

Ing. Ricardo Mongez López

Director de la Facultad de Ciencias, UNAM

Miembro de la Comisión Impulsora

y Coordinadora de la Investigación

Científica

Dr. Fernando Orozco Díaz 
Tabla 1 (concluye)

\begin{tabular}{ll}
\hline Ing. Federico Barona de la O & $\begin{array}{l}\text { Jefe del Instituto de Química de la UNAM } \\
\text { Jefe de Laboratorios de Ensayo y } \\
\text { Materiales de la Comisión Nacional de } \\
\text { Irrigación }\end{array}$ \\
Ing. Carlos Bermúdez Lacayo & $\begin{array}{l}\text { Jefe de la Sección Química, Departamento } \\
\text { de Gerencia de Refinerías, Petróleos } \\
\text { Mexicanos }\end{array}$ \\
\hline
\end{tabular}

Notas: * Si bien Eduardo Suárez aparece en la lista de invitados, es probable que no haya asistido pues no aparece ninguna intervención suya en la conferencia. Es probable que haya asistido Roberto Garza en lugar de Rómulo Garza, pues es de este último de quien se hace mención en los reportajes del acto.

Fuente: Armour Research Foundation, Proceedings, pp. ix-x.

Como parte del programa la ARF les organizó una serie de conferencias y visitas a los principales laboratorios de investigación de la región de Chicago, que además de los laboratorios de la ARF, incluían los de las principales universidades, como los de la Universidad de Chicago, Northwestern, Wisconsin, y Purdue, y laboratorios pertenecientes a compañías privadas, como los de General Electric, o el de Universal Oil Products Company, que presentaron los distintos desarrollos y proyectos de investigación que estaban llevando a cabo. ${ }^{42}$ Además, se impartieron diversas pláticas sobre el funcionamiento e importancia de la Asociación de Estándares Americana y la Oficina Nacional de Estándares en el desarrollo industrial. Asimismo, varios de los directivos de laboratorios industriales en Estados Unidos describieron su forma de operación y financiamiento subrayando la importancia de los fondos donados por individuos o empresas para su funcionamiento. Como respuesta a estas exposiciones, Eduardo Villaseñor expuso su percepción sobre la situación que enfrentaba México en el campo de la investigación:

42 “Mexican-American Conference" (7 de noviembre de 1945). 
Para algunos de nuestros amigos americanos, que no conocen lo que se está haciendo en México, debo de corregir la idea que puedan tener de que existen en México instituciones de investigación y fundaciones como las que tienen aquí. No existe ninguna de ellas en México - no hay fundaciones, no hay instituciones de investigación y no hay universidades con fondos para operar de forma independiente como tienen aquí sus universidades-. La más importante y destacada universidad en México, que es una de las más viejas del hemisferio -la Universidad Nacional de México- [...] es realmente una institución gubernamental con recursos bastante limitados para llevar a cabo su tarea. Por tanto, si con dificultad puede pagar los muy bajos salarios de sus maestros y profesores, ¿cómo podría conseguir los recursos para llevar a cabo investigación? No existe tal cosa. ${ }^{43}$

Explicaba que hacía unos tres años se había establecido en el Banco de México un departamento de investigación industrial, muy pequeño, considerando el número de personas que trabajaban en él, pero ambicioso en términos del programa que perseguía cubrir. Si bien existían otras instituciones, como el Instituto de Química y el Instituto de Física, emprendían su trabajo con recursos muy limitados. Un problema adicional era que "no tenemos en México millonarios en el sentido que ustedes usan la palabra”. En México, explicaba, los millonarios que existían eran recientes, es decir, personas que no tenían millones diez años atrás, “y que no han tenido ejemplo a seguir sobre cómo usar sus millones”. ${ }^{44}$ Además, a diferencia de Estados Unidos, en donde existía una tradición de donar fondos o becas a instituciones de espíritu público como universidades o centros de investigación, eso no existía en México.

${ }^{43}$ Intervención de Eduardo Villaseñor en Weidlein, “The Organization”, pp. 35-36.

${ }^{44}$ Intervención de Eduardo Villaseñor, en Weidlein, p. 36. 
Ante este escenario, expresó, desde que fue nombrado gobernador del Banco de México supo que era momento de hacer algo al respecto. "Tenemos que crear, y creo que es parte de los propósitos no escritos de la Armour Research Foundation" [para organizar esta conferencia] "[...] el imbuir a algunos de los miembros mexicanos, la idea de lo importante que es la investigación, y la importancia de contar con donaciones, becas y fondos para llevar a cabo este tipo de trabajo" ${ }^{45}$ Sin embargo, esto no era fácil, pues en México no existía ninguna universidad que pudiera establecer un fondo para crear un instituto de investigaciones como los que habían visitado, y el Banco de México estaba, a su juicio, un tanto fuera de su campo para hacerlo. "No puede esperarse que el Banco de México [...] establezca en un día un fondo de 5 o 10 millones de pesos para crear una institución como esta". Sin embargo, vislumbraba la posibilidad de que el Banco de México sirviera como catalizador, "y que pudiera inducir a algunas de las instituciones o individuos más ricos a contribuir a la creación de instituciones que lleven a cabo la investigación fundamental e industrial". ${ }^{46}$

En su discurso final en la conferencia, Eduardo Villaseñor relató que la noche anterior había soñado que se sacaba la lotería y que usaba ese dinero para crear en México un instituto de investigaciones industriales. Seguramente, la visita a distintas instituciones de investigación lo dejó profundamente entusiasmado con la idea de crear algo similar en México, y a la vez sentía una gran inquietud por no poder reunir los recursos para hacerlo. Buscando la forma de logar el objetivo, explicó que tras su regreso, el Banco de México convocaría a los delegados que asistieron a la conferencia, y a otros industriales que quisieran sumarse, para examinar los pasos que había que dar para llevar a cabo este proyecto. Contemplaba distintas posibilidades para lograrlo, ya sea

45 Intervención de Eduardo Villaseñor, en WEIDLEIN, p. 37.

46 Intervención de Eduardo Villaseñor, en WEIDLEIN, p. 37. 
con la participación exclusiva de instituciones privadas, o de instituciones gubernamentales, o mediante la cooperación de ambas. ${ }^{47}$

Asimismo, durante la conferencia el Ing. Barona de la $\mathrm{O}$, jefe de los laboratorios de la Comisión Nacional de Irrigación, destacó que la Secretaría de Economía estaba tomando los pasos necesarios para formar pronto los Laboratorios Nacionales de Fomento Industrial, que apoyarían a la Dirección General de Normas. ${ }^{48}$ Es interesante señalar que la conferencia se grabó por medio de la reciente tecnología de registro en cinta magnética que había desarrollado precisamente la ARF. Una copia de esta le fue enviada al presidente Manuel Ávila Camacho, junto con una carta por parte de la ARF. ${ }^{49}$

Después de la Conferencia de Chicago, el Banco de México organizó una reunión que había sugerido Eduardo Villaseñor y se sostuvieron una serie de pláticas informales con varios de los participantes a fin de obtener sus opiniones. Finalmente, el Banco de México reunió a un grupo más amplio para exponer las conclusiones a las que se había llegado y conocer los puntos de vista que sobre ellas tenían diversos representantes del gobierno, la banca, la industria y el sector educativo y técnico, así como de la ARF.

\section{EL PROYECTO DEL INSTITUTO MEXICANO}

DE INVESTIGACIONES TECNOLÓGICAS

Tomando en cuenta las ideas desarrolladas en estas discusiones, la ARF realizó un proyecto para crear el Instituto Mexicano de

\footnotetext{
47 Intervención de Eduardo Villaseñor en la conferencia "Discussion by Mexican Guests”, en Armour Research Foundation, Proceedings, pp. 157-158. 48 Intervención del Ing. Barona de la $\mathrm{O}$ en la conferencia "Discussion by Mexican Guests”, en Armour Research Foundation, Proceedings, pp. 157-158.

49 Intervención de J. E. Hobson en la conferencia “Discussion by Mexican Guests”, en Armour Research Foundation, Proceedings, pp. 150-151.
} 
Investigaciones Tecnológicas, que plasmó en el capítulo final del informe que entregó al Banco de México en febrero de 1946.50 Este incluía recomendaciones detalladas para su establecimiento, inspiradas en el sistema de operaciones patrocinadas que llevaba a cabo la ARF en Estados Unidos. ${ }^{51}$

El informe empezaba señalando que era crucial para México establecer una institución de investigaciones industriales puesto que estaba demostrado que "tanto en términos de los cerebros, como de las instalaciones físicas, la ganancia en tecnología industrial bajo un sistema de esfuerzo cooperativo es mucho mayor que la que se consigue por esfuerzos dispersos del mismo número de personas trabajando individualmente".$^{52} \mathrm{Si}$ esto era cierto incluso en los países desarrollados, en México, dada su limitada oferta de personal técnico, era imperativo concentrar su esfuerzo en una institución.

Dicha institución debía centrarse en resolver los problemas de México por medio de proyectos de investigación que, debido a su distinta naturaleza, habían de sufragarse de diversas formas. Los programas de investigación de amplio beneficio para toda la República o para amplias regiones del país, así como investigaciones encomendadas por dependencias gubernamentales, debían sufragarse con el apoyo económico del gobierno. En cambio, los programas confidenciales de investigación y fomento para compañías privadas habían de costearse por la entidad interesada, debiendo permitirse que ésta adquiriera el derecho exclusivo sobre los resultados, incluyendo cualquier patente que se obtuviera. Los programas de investigación de beneficio para

50 Armour Research Foundation, Technological Audit, pp. 174-184; UREncio, “Investigación Tecnológica en México”, p. 459.

${ }^{51}$ Ignacio Deschamps, "Programa de investigación aplicada actualmente en Operación en el Instituto Mexicano de Investigaciones Tecnológicas”, mimeo, texto presentado ante el American Institute of Mining, Metallurgical \& Petroleum Engineers, Mexico Section, junio de 1959, p. 2.

52 Armour Research Foundation, Technological Audit, p. 174. 
todos los miembros de una industria podrían ser costeados por una asociación de empresas, o por algún departamento del gobierno que tuviera interés en apoyar a esa industria. El Instituto debería ofrecer también servicios de consultoría para ayudar a la modernización de fábricas mexicanas y operaciones industriales a costos razonables que serían pagados por las empresas interesadas. Este tipo de servicios deberían enfocarse a las pequeñas empresas que no pudieran sufragar los gastos de traer expertos extranjeros para hacer trabajos de inspección y consulta. ${ }^{53}$

El modelo que proponían seguía de cerca el sistema que venía desarrollándose en Estados Unidos, en el que la investigación industrial era patrocinada por las industrias a título individual. Sin embargo, integraba también un importante componente de participación directa del estado como promotor del desarrollo tecnológico, como lo venían realizando otros países, como Inglaterra y Holanda. ${ }^{54}$ Se partía del principio de que la industria privada debía cubrir una parte justa de la carga, en proporción a los beneficios privados que esperaba recibir, pero que debía también considerarse la posibilidad de que el gobierno cubriera, durante cierto tiempo, alguna fracción de los costos de la investigación enfocada a las empresas privadas, como un incentivo para que usaran servicios técnicos y de investigación. Esta estrategia, explicaban, se había venido empleando en el estado de Sao Paulo, en su Instituto de Pesquisas Tecnológicas. También podría considerarse que el gobierno ofreciera deducciones de impuestos o crédito de los montos gastados en investigación, como se hacía en Estados Unidos. ${ }^{55}$

\footnotetext{
53 Armour Research Foundation, Technological Audit, pp. 174-175.

54 "Reseña del Instituto Mexicano de Investigaciones Tecnológicas, tomada del discurso pronunciado por su Director General con motivo del 25 aniversario de su fundación, y de la conferencia sustentada por el mismo en la reunión Latinoamericana y del Caribe sobre servicios de consultoría.” IMIT, Actas del Consejo Directivo (ACD), No. 111, 4 de julio de 1975.

55 Armour Research Foundation, Technological Audit, p. 176.
} 
En términos generales, el Instituto debería servir como un centro de investigación industrial, estimulando con sus acciones el interés de las industrias en la investigación y la adopción de mejores prácticas, así como el interés de los estudiantes en seguir cursos en tecnología industrial aplicada..${ }^{56}$ Su política debía guiarse por tres principios clave: 1) el principal objetivo del Instituto era servir a la industria, 2) el desarrollo tecnológico de México requería aprovechar los avances realizados en el resto del mundo para desarrollar sus propias capacidades, por lo que no debía seguir políticas aislacionistas y, 3) el Instituto debía tener autonomía pues una institución de investigación debe operar bajo condiciones que jamás pueden lograrse por el control del gobierno.

Para servir a la industria, el Instituto necesitaba ser capaz de conducir proyectos de investigación completamente confidenciales, obtener patentes y mejorar productos para el beneficio exclusivo de las compañías a las que sirviera. Además, debía poder conducirse de forma ágil y eficiente y no sujetarse a consideraciones políticas. "No hay una imagen más trágica" señalaba "que un laboratorio de investigación que se ha vuelto burocrático en su operación, ya que cuando esto pasa, la productividad cae y se reduce a una derrama delgada en proporción a los costos". 57

En cuanto a la definición de la estructura organizacional del Instituto, el informe proponía tomar como modelo la adoptada por otras instituciones de investigación exitosas. Se proponía por tanto que su control recayera en un Consejo Directivo, que idealmente incluiría a líderes de la industria, las finanzas y el servicio público; personas activas, de influencia y genuinamente interesadas en el Instituto y sus esfuerzos hacia la industria mexicana. El presidente del Consejo debería ser mexicano, así

56 Armour Research Foundation, Technological Audit, pp. 177-178.

57 Armour Research Foundation, Technological Audit, p. 176. 
como la mayoría de sus miembros. El director general, quien debía ser designado por el Consejo por un tiempo indefinido, tendría la responsabilidad y autoridad de la organización, desarrollo y operación del Instituto y la administración general de las políticas que determinara el Consejo. Se planteaba que, en el largo plazo, sería natural y deseable que el director fuera mexicano, pero considerando que en ese momento era posible que no existiera ningún mexicano con la experiencia de haber administrado un instituto de investigaciones industriales, había que dejar abierta la posibilidad de elegir a un extranjero. Asimismo, sugería que la dirección técnica y ejecutiva se basara, en un primer momento, en un arreglo cooperativo entre personal mexicano y extranjero, considerando que era imperativo traer al Instituto toda la experiencia acumulada en la conducción de investigaciones industriales. "De esta forma se combinarían el conocimiento básico y esencial de las condiciones y problemas existentes en México, con los últimos adelantos de la técnica de la investigación". 58

En relación con el perfil que debería tener el director, advertían que no debía caerse en el error de creer que, por tratarse de una entidad científica, este debía ser un científico eminente, que, en general, no son personas aptas para dicho puesto. En cambio, debía nombrarse a alguien que supiera de la administración de un instituto de investigaciones industriales. Recomendaban que el director fuera una persona "con una formación técnica general, y con una iniciativa, habilidad administrativa e imaginación excepcionales”, y que fuera joven, pues “la investigación es primordialmente un asunto de jóvenes”, y un joven es más adaptable a los cambios rápidos. ${ }^{59}$

Sugerían que el personal de investigación fuera integrándose gradualmente, contratando en un principio sólo al núcleo del

\footnotetext{
58 Armour Research Foundation, Technological Audit, pp. 179-180.

59 Armour Research Foundation, Technological Audit, p. 180.
} 
cuerpo de investigadores, que se iría reforzando conforme lo fueran exigiendo las necesidades del trabajo. Un asunto fundamental era establecer sueldos lo suficientemente atractivos para poder contratar a los mejores tecnólogos, y que pudieran trabajar de tiempo completo. "Es obvio" decía el informe "que una de las razones por las cuales faltan tecnólogos en México es que se puede ganar mucho más dinero en otras actividades", y "si el nuevo Instituto perpetúa tales condiciones no se habrá ganado nada". ${ }^{60}$

Asimismo, recalcaban la necesidad de poner énfasis en el entrenamiento del personal de investigación mexicano que se requeriría, puesto que, si bien muchos técnicos mexicanos contaban con sobresalientes bases teóricas, no habían tenido la oportunidad de adquirir experiencia en investigaciones tecnológicas prácticas. Para resolver este problema, proponía que el Instituto comenzara con un personal compuesto de técnicos mexicanos e investigadores extranjeros, que trabajarían como un grupo unificado y compartirían su trabajo en los problemas de laboratorio. Al mismo tiempo, otro grupo de tecnólogos mexicanos serían enviados a instituciones de investigación en Estados Unidos y otros países, también para trabajar junto a investigadores experimentados, por uno o dos años allá, al cabo de los cuales regresarían para integrarse como miembros del equipo de la institución mexicana. ${ }^{61}$

En cuanto a las instalaciones físicas del Instituto, advertían sobre la importancia de no cometer el error de invertir una cantidad desproporcionada en los edificios de laboratorio y el equipo, que al final resultaran inadecuadas y se acabaran convirtiendo en elefantes blancos, como recientemente le había sucedido a una petrolera latinoamericana. ${ }^{62}$ En cambio, proponían que se

60 Armour Research Foundation, Technological Audit, p. 181.

${ }^{61}$ Armour Research Foundation, Technological Audit, pp. 183-184.

62 Armour Research Foundation, Technological Audit, p. 182. 
comenzara a trabajar en instalaciones provisionales, con un programa de investigación diversificado que pudiera enfocarse en los programas de investigación de interés práctico para los que hubieran encontrado patrocinadores. Estas no deberían ser más grandes que lo que requirieran los proyectos en curso, de modo de no aumentar el costo de la investigación. Con el tiempo, podrían conocerse mejor las necesidades del Instituto, y sólo hasta entonces habría que pensar en el diseño del edificio que debería alojarlo de forma permanente. Lo fundamental era establecer desde un inicio una biblioteca técnica bien abastecida y actualizada. La ARF consideraba que, para poder comenzar, el Instituto requeriría de un fondo mínimo de 2.5 millones de pesos para cubrir el establecimiento de instalaciones temporales, los costos básicos de operación y los salarios de un personal inicial. ${ }^{63}$

\section{LOS PRIMEROS PASOS: LA COOPERACIÓN}

DE LA ARF Y EL IMIT (1947-1954)

Originalmente se buscaba que en México se adoptara un modelo similar al de Estados Unidos, en donde existía una amplia participación privada en el sistema de investigación científica y tecnológica. Sin embargo, tras la conferencia en Chicago y luego de las distintas reuniones con empresarios, Eduardo Villaseñor comprendió que, si se quería que un instituto de investigaciones industriales se hiciera realidad en México, el Banco de México tendría que encabezar y financiar el proyecto, lo que llevó a cabo tomando en cuenta las recomendaciones que había hecho la ARF en su informe. ${ }^{64}$

En 1947 el Banco de México solicitó a la ARF que iniciara el proyecto de establecer un instituto de investigación industrial

63 Armour Research Foundation, Technological Audit, p. 183; Urencio, “Investigación Tecnológica”, p. 459.

64 "Proposición para la creación de un Instituto de Investigaciones Tecnológicas”, AGN, fondo Gonzalo Robles, c. 58, exp. 4. 
para lo que estableció un pequeño laboratorio en la calle Mazatlán núm. 119, en la Ciudad de México. Su dirección técnica y administrativa estuvo a cargo de la ARF e inició combinando los esfuerzos de tecnólogos mexicanos y de la ARF en trabajos de investigación seleccionados por el Banco de México. Pronto resultó evidente que era necesario contar con instalaciones más amplias. En 1949, comenzó a construirse un nuevo edificio en la Calzada Legaria núm. 694, para establecer los laboratorios y tener espacio para instalar plantas piloto. El Banco de México encomendó a la ARF la dirección técnica del diseño y construcción de las nuevas instalaciones y aportó los recursos necesarios para lograrlo.

Una vez concluidas las nuevas instalaciones, el 1o de junio de 1950 se constituyó formalmente el Instituto Mexicano de Investigaciones Tecnológicas (IMIT). ${ }^{65} \mathrm{El}$ Banco de México logró sumar a Nacional Financiera para patrocinar el proyecto y poco después el Bancomext se constituyó en la tercera institución que habría de apoyar al Instituto. ${ }^{66} \mathrm{~A}$ pesar de no haber sido el objetivo inicial, el que estos tres bancos estatales resultaran siendo los patrocinadores del IMIT terminó dando al Instituto una ventaja, ya que lo salvó de "una situación de cautiverio" que le coartara la libertad necesaria para su acción eficaz. ${ }^{67}$

$\mathrm{Al}$ establecerse el IMIT, este se hizo cargo de los laboratorios y proyectos que hasta entonces venía desarrollando la ARF y su administración pasó a manos de mexicanos, en tanto que la dirección técnica de los programas de investigación continuó siendo encomendada a un representante de la ARF, al doctor

\footnotetext{
65 Armour Research Foundation, “Direction of the Laboratories”, p. 3.

${ }^{66}$ Ignacio Deschamps, "Programa de Investigación Aplicada Actualmente en Operación en el Instituto Mexicano de Investigaciones Tecnológicas”, mimeo, texto presentado ante el American Institute of Mining, Metallurgical \& Petroleum Engineers, Mexico Section, junio de 1959, pp. 2-3.

67 "Reseña del Instituto Mexicano de Investigaciones Tecnológicas", IMIT, ACD, No. 111, 4 de julio de 1975, p. 2.
} 
M. E. Nelson. El personal de investigación estaba conformado por un núcleo de siete científicos e ingenieros mexicanos, con estudios de posgrado en el extranjero, que trabajaban junto a científicos e ingenieros de la ARF. Este grupo era complementado con personal que ofrecía servicios de biblioteca y diseño, secretarias bilingües y personal no técnico que apoyaba en los laboratorios, así como un pequeño equipo de contadores que registraba los gastos de cada proyecto.

Cada año se fueron sumando nuevos integrantes a quienes se capacitaba en las técnicas de investigación industrial por la ARF. Hacia 1954 ya había 23 miembros del personal técnico, 6 de los cuales tenían un mínimo de seis años de experiencia en la investigación industrial y se desempeñaban como jefes de las distintas secciones. ${ }^{68}$ El IMIT contaba para entonces con seis laboratorios especializados en distintos campos de investigación, un laboratorio de operación integrada, y estaba en construcción una pequeña planta piloto. ${ }^{69}$ Parte de los equipos de laboratorio fueron donados por fabricantes de equipo o vendidos a un costo reducido. ${ }^{70}$

Cada año la ARF enviaba al IMIT personal de alto nivel y personal técnico calificado para asistir a los distintos equipos, con quienes mantenía comunicación por medio de correspondencia, que sumaba más de 200 comunicaciones anuales. ${ }^{71}$ Durante sus primeros años, el Instituto contó también con el apoyo de especialistas de la Food and Agricultural Organization (FAO)

${ }^{68}$ Ignacio Deschamps, "Programa de Investigación Aplicada Actualmente en Operación en el Instituto Mexicano de Investigaciones Tecnológicas”, mimeo, texto presentado ante el American Institute of Mining, Metallurgical \& Petroleum Engineers, Mexico Section, junio de 1959, pp. 4 y 25-27.

69 Armour Research Foundation, "Direction of the Laboratories", pp. vi-vii.

70 Armour Research Foundation, "Direction of the Laboratories", p. 27.

71 Armour Research Foundation, "Direction of the Laboratories", pp. 21-22. 
de Naciones Unidas, así como de algunas universidades y estaciones experimentales de Estados Unidos. ${ }^{72}$

Durante sus primeros años, "los estudios del IMIT eran marcadamente los concernientes a las materias primas del país" mediante los cuales el Instituto "pudo cubrir un gran número de recursos industriales y revisar a nivel de laboratorio y de equipo piloto las más variadas alternativas de los procesos industriales de base". ${ }^{73}$ Estos fueron propuestos por las instituciones patrocinadoras a partir de las recomendaciones que había hecho la ARF en su auditoría tecnológica. En un principio, los proyectos de investigación se abordaron "con recursos propios que sirvieron como base para la generación del acervo tecnológico inicial del IMIT y como sustentación del adiestramiento intensivo de su personal en técnicas de investigación aplicada". ${ }^{74}$ Sin embargo, poco a poco se fueron sumando proyectos patrocinados por empresas privadas.

Para seleccionar los proyectos de investigación, el IMIT realizaba un estudio preliminar técnico y económico con el fin de evaluar sus posibilidades de generar un impacto económico real. Una vez elegido, se definía un líder del mismo, quien coordinaba un equipo compuesto de científicos e ingenieros. Asimismo, se conformaba un Comité Directivo, que incluía, representantes de los grupos de servicios generales, científicos o ingenieros de otras secciones y supervisores del Instituto, así como a algún representante de las instituciones patrocinadoras. ${ }^{75}$

Todo proyecto comenzaba con un amplio estudio de la literatura existente, a partir de la cual se formulaba un plan de

\footnotetext{
72 Armour Research Foundation, "Direction of the Laboratories", p. 4.

73 "Reseña del Instituto Mexicano de Investigaciones Tecnológicas", IMIT, ACD, No. 111, 4 de julio de 1975, p. 2.

74 "Breves antecedentes sobre el desarrollo del IMIT que expone el Director General de la Institución”, IMIT, ACD, No. 131, 19 de mayo de 1978, pp. 3-4. 75 Armour Research Foundation, "Direction of the Laboratories", pp. $17-22$.
} 
investigación. Luego se hacía una inspección de las materias primas, tanto técnica como económica. A esto seguía una evaluación de sus costos y beneficios posibles, que era realizada por el equipo económico, que fue complementado, en un principio, con personal del Departamento de Investigaciones Industriales del Banco de México y de Nafinsa. Una vez que se identificaba que existía una probabilidad razonable de éxito, comenzaba la investigación de laboratorio, que iniciaba por una caracterización de los materiales (materias primas, microorganismos, enzimas, etc.) que se utilizarían. Entonces se emprendía la investigación de laboratorio del proceso, a la que seguía la elaboración de un diagrama cuantitativo del balance de flujo para identificar la solución más efectiva y económica que ofreciera una calidad aceptable a un costo razonable.

Una vez definido el proceso óptimo se realizaba un estudio de factibilidad económica para evaluar su probable rentabilidad a escala industrial. Concluida esta fase, se realizaba la investigación de operaciones y procesos integrados, en la que se definían los equipos y procesos que requeriría la planta industrial. Finalmente, cuando se consideraba necesario, se construía una planta piloto. mediante la cual se realizaba una producción semicomercial de los productos que se contemplaba ofrecer en el mercado. A partir de los resultados de la planta piloto se realizaban los estudios finales de ingeniería y de factibilidad económica. Para reducir costos, el IMIT ideó adquirir equipo versátil que podía utilizarse en la fase de desarrollo de varios proyectos, pues podía interconectarse de distinta forma para cada uno de ellos. ${ }^{76}$

Entre 1950 y 1954 el IMIT emprendió 130 proyectos formalmente establecidos, de los cuales 9 fueron de largo alcance, con una duración de más de un año. El resto fueron proyectos de corta duración que, junto con los servicios de asesoría,

76 Armour Research Foundation, "Direction of the Laboratories", pp. 8-17. 
hicieron contribuciones valiosas a las organizaciones y empresas que los financiaron en relación con procesos, maquinaria, patentes o uso de materias primas. Entre los proyectos de largo alcance, que se consideraba tendrían un impacto importante en el desarrollo industrial del país se encontraban: el desarrollo de la harina de maíz nixtamalizado que representó un cambio radical sobre el proceso tradicional; la estabilización y enriquecimiento nutricional de la harina de maíz nixtamalizado mediante la mezcla de proteínas de soya, garbanzo y cacahuate; el desarrollo de un sustituto del carbón vegetal utilizando carbón semiantracítico de Oaxaca y carbón antracítico de Sonora; el estudio de aceites vegetales a partir de plantas y semillas poco conocidas, como la jojoba, para identificar sus propiedades químicas y posibles usos; el desarrollo de cera de los desechos de la industria del henequén; el desarrollo de taninos vegetales a partir del cascalote y de otras plantas; el desarrollo de productos industriales a partir del garbanzo, tales como almidón, proteínas, aceites o fibras; la desfibración del kenaf (Hibiscus cannabinus), que es una fibra similar al yute; y el estudio de la pulpa de celulosa y de papel, en el que se evaluaron los recursos de celulosa y las plantas industriales de pulpa y papel existentes en el país para mejorar su calidad y costos de operación. Además, se desarrollaron alternativas para producir la pulpa a partir de bagazo de caña de azúcar y maderas tropicales con el fin de hacer papel periódico a partir de pulpa mexicana.

Durante este periodo, el Instituto envío 17 solicitudes de patente, 6 de las cuales ya habían sido otorgadas. Entre las primeras destacan: las patentes básicas para la producción de tortilla de maíz en México, Estados Unidos y El Salvador; la patente para la extracción de pectinas de los desechos del henequén; la extracción centrífuga de taninos y la de una máquina de cintas de kenaf. Las que estaban aún en proceso incluían la de un proceso mejorado de extracción de taninos; tres procesos para separar la cutícula del bagazo del henequén; un procedimiento mejorado 
para obtener cera de candelilla y pulpa de celulosa en la misma operación; y dos procesos mejorados para lograr harina de maíz nixtamalizado. ${ }^{77} \mathrm{La}$ tabla 2 incluye las patentes otorgadas a favor del Banco de México o del IMIT, pero no comprende aquellas que se otorgaron a favor de empresas patrocinadoras.

Uno de los logros más importantes del IMIT fue el desarrollo del proceso para la producción de harina estable de maíz para la preparación de tortillas, que avanzó hasta servir de base para el diseño industrial de la planta de Maíz Industrializado S. A. (MINSA), establecida por el gobierno en Tlalnepantla, así como para las plantas de la empresa Quaker Oats, que estableció en Sherman, Texas y Los Ángeles, California, cuyas regalías beneficiaron al IMIT durante los 15 años de vigencia de las patentes correspondientes, propiedad del Instituto. ${ }^{78}$

El desarrollo del IMIT sirvió de base para que se establecieran institutos similares en otros países latinoamericanos. En enero de 1950, la ARF fue contratada por el gobierno de El Salvador para realizar una auditoría tecnológica, similar a la que había realizado para México algunos años atrás, y después dirigió la instalación y puesta en operación de un laboratorio de investigación industrial..$^{79}$ Asimismo, colaboró con el gobierno colombiano en la conformación del Instituto de Investigaciones Tecnológicas de Colombia, que se estableció en $1955 .{ }^{80}$

77 Armour Research Foundation, "Direction of the Laboratories", pp. 53-54.

${ }^{78}$ Ignacio Deschamps, "Programa de Investigación Aplicada Actualmente en Operación en el Instituto Mexicano de Investigaciones Tecnológicas”, mimeo, texto presentado ante el American Institute of Mining, Metallurgical \& Petroleum Engineers, Mexico Section, junio de 1959, pp. 12-13; Ignacio Deschamps, "Palabras pronunciadas por el señor Ignacio A. Deschamps Aguilar, en el homenaje que se le dio en el IMIT, con motivo de su retiro como Director General de la institución, en 1982", Mimeo.

79 Armour Research Foundation, "Preliminary technological audit".

80 Young, "El Instituto", pp. 55-56; Ayala, "The Colombian Institute”, pp. 12-16. 


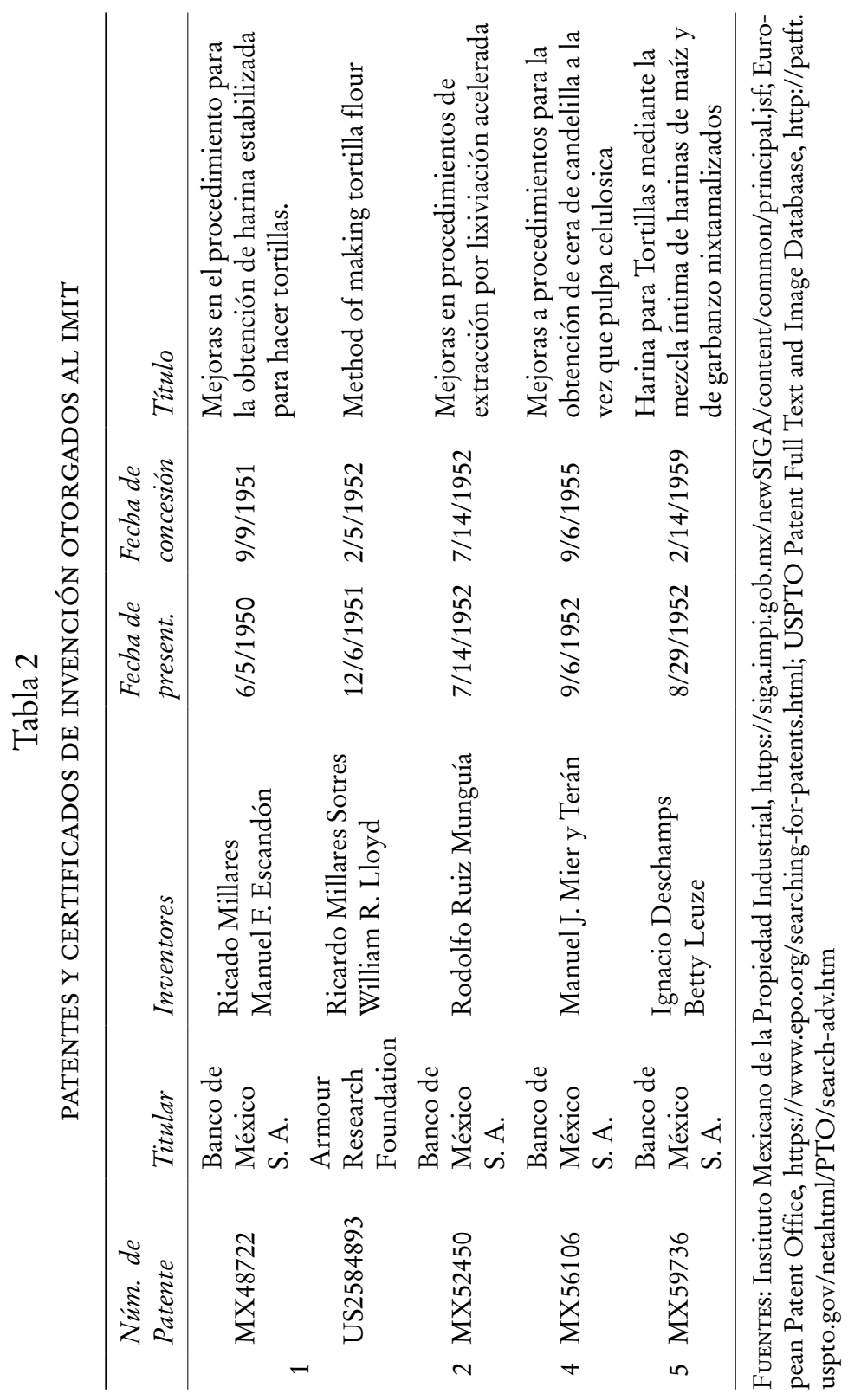




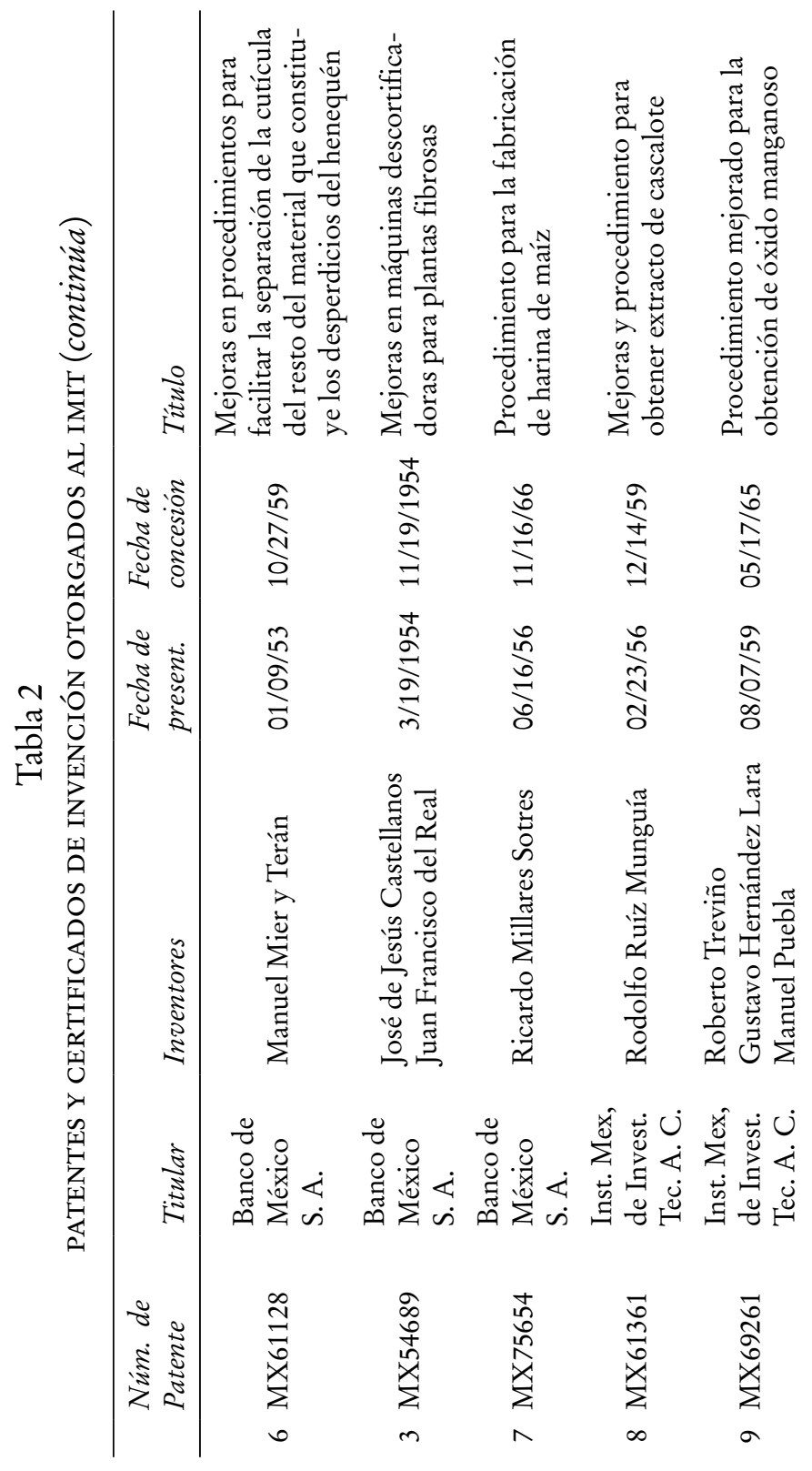




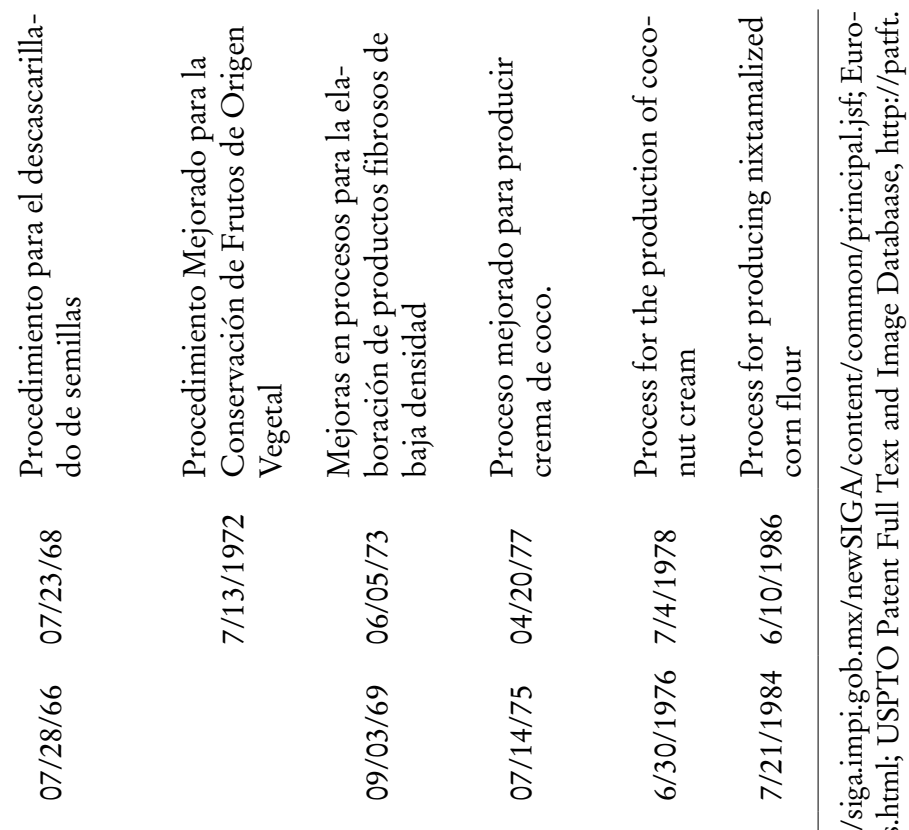

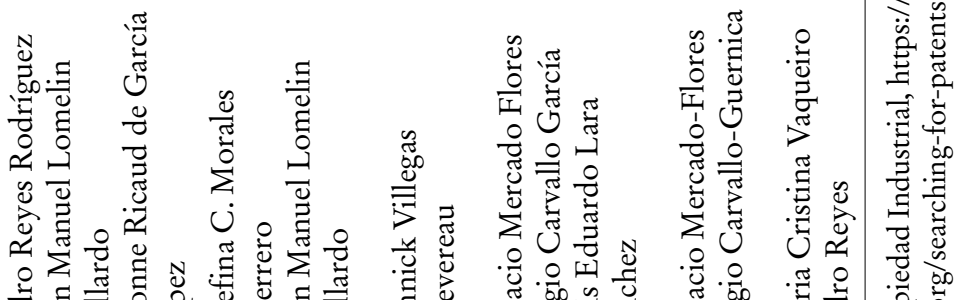

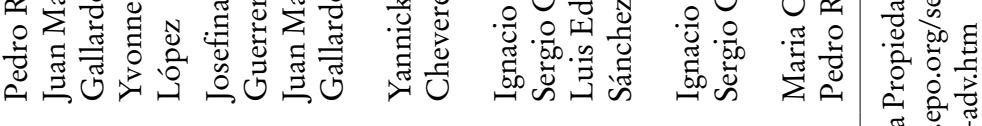

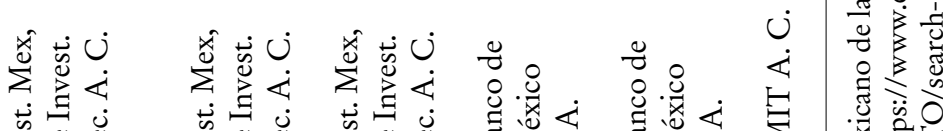

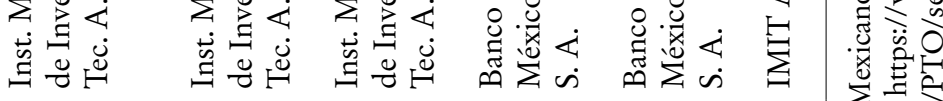

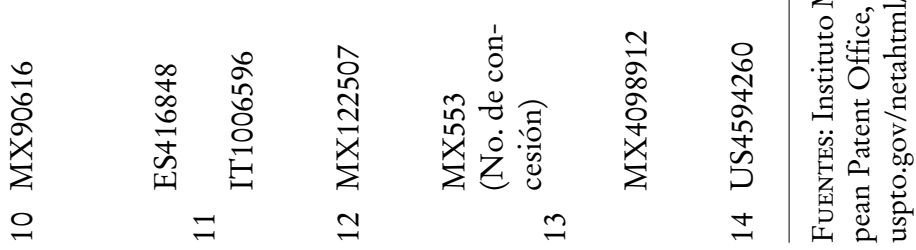




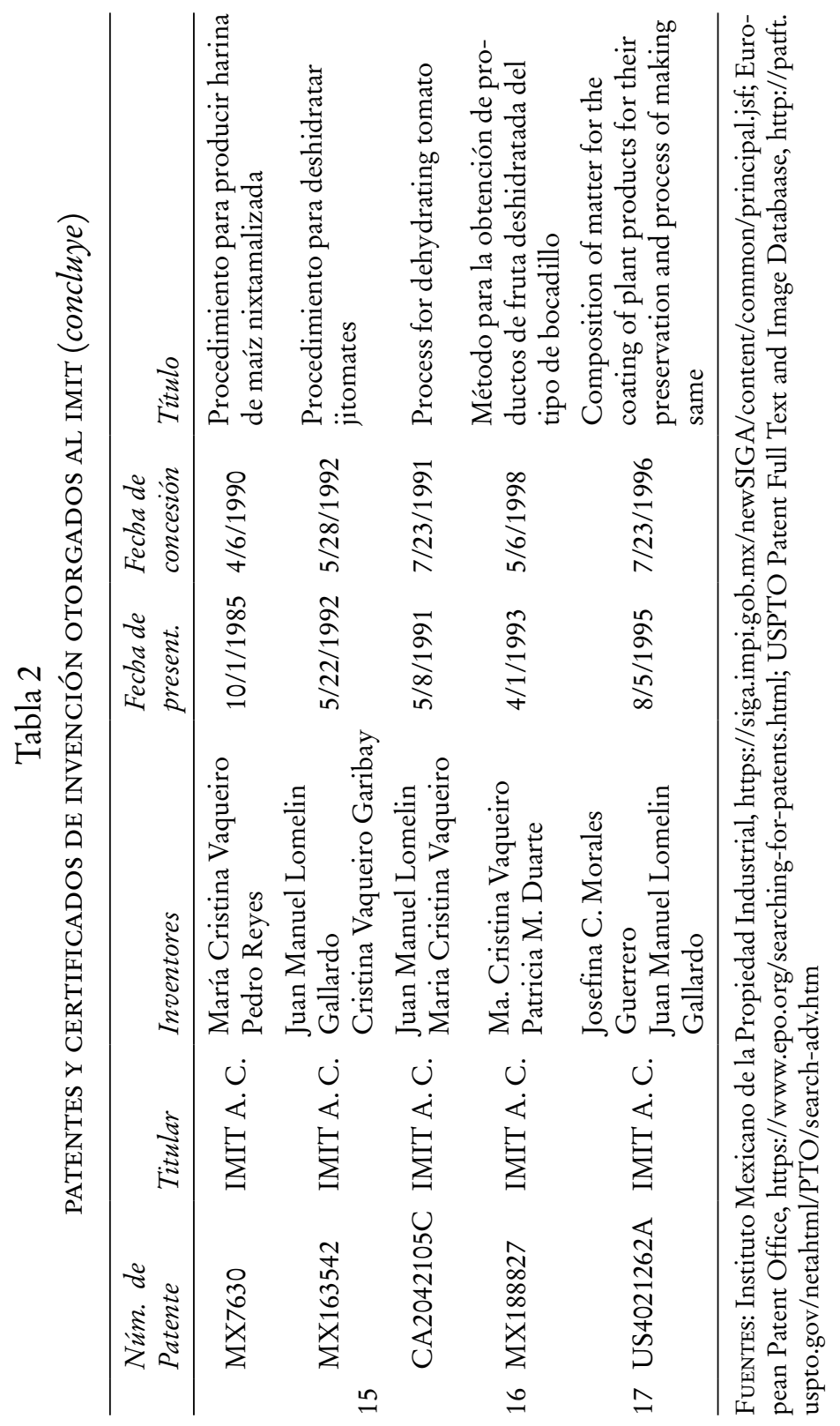




\section{LA MEXICANIZACIÓN DEL IMIT}

A partir de octubre de 1954 el IMIT entró en una nueva fase en la que, tanto la dirección administrativa como la dirección técnica, fueron encomendadas a mexicanos que venían trabajando en el Instituto. Se nombró como director del instituto al Lic. Manuel Bravo Jiménez (1917-2012), licenciado en economía por la Universidad Nacional Autónoma de México (UnAM), quien llevaba años trabajando en el Banco de México. ${ }^{81}$ Por su parte, en la Dirección de Investigación se nombró a Ignacio Deschamps Aguilar (1923-2008), químico farmacobiólogo, egresado de la Facultad de Ciencias Químicas de la UNAm con estudios de posgrado en química orgánica en la Universidad Fordham, Nueva York. ${ }^{82}$ Ignacio Deschamps ingresó a trabajar en el laboratorio de la ARF en agosto de 1949, antes de que se constituyera formalmente como IMIT, como investigador del Departamento de Bioquímica Aplicada. En 1954, se convirtió en el director general del Instituto, permaneciendo en esta función por casi 30 años, hasta $1982 .{ }^{83}$

A partir de 1954 la ARF dejó de tener injerencia interna en el IMIT, sin embargo, inicialmente dos investigadores de la ARF permanecieron en el IMIT, financiados por un convenio con la International Cooperation Administration de Washington D. C. ${ }^{84}$ Luego, siguió ofreciendo asesoría especializada cuando

${ }^{81}$ Antes de ingresar a la Facultad de Economía, estudió en la Escuela Nacional de Maestros y trabajó como maestro rural. Después de fungir como director del IмIт promovió e impulsó el Centro Nacional de Productividad, del cual fue director general; más adelante fue rector de la Escuela Nacional de Pedagogía.

${ }^{82}$ Cédula Profesional No. 21820, http://cedula.buholegal.com/21820/ (consultado el 28 de abril de 2017).

83 Jesús González Schmal, "Una sensible ausencia”, El Universal (26 ene. 2008).

${ }^{84}$ Ignacio Deschamps, "Programa de Investigación Aplicada Actualmente en Operación en el Instituto Mexicano de Investigaciones Tecnológicas”, mimeo, 
los problemas técnicos lo requerían. ${ }^{85}$ Por medio de la ARF, el IMIT contó con el apoyo de numerosas industrias y centros de investigación extranjeros, principalmente de Estados Unidos. ${ }^{86}$ Con el tiempo, el IMIT fue ampliando sus lazos con otras instituciones de investigación, lo que le permitió disminuir su dependencia de la ARF.

A principios de 1958, el IMIT se constituyó en fideicomiso, con el Banco de México como entidad fiduciaria y el propio Banco, Nafinsa y el Bancomext como los Fideicomitentes. Con esta decisión, el IMIT fue dotado de una fórmula jurídica más independiente, que le brindaba la autonomía que había sido recomendada por la ARF. A partir de entonces, el presupuesto de operación del IмIт ya no dependió exclusivamente de los fondos provenientes de las tres instituciones patrocinadoras permanentes, sino que éste fue complementado con fondos suministrados por las industrias y organizaciones que requerían de su asistencia técnica.

A partir de 1954 el instituto se organizó formalmente en divisiones definidas en torno de las materias primas y productos a los que se enfocaba la investigación (véase la tabla 3). Dicha organización se fue modificando, por lo que para 1959 las divisiones se reestructuraron de acuerdo con los campos de la química involucrados en el desarrollo de los proyectos.

Estos años fueron también una etapa de intensa capacitación en los que el Instituto adiestró, con apoyo en un programa especial del Banco de México, a numerosos becarios. ${ }^{87}$

texto presentado ante el American Institute of Mining, Metallurgical \& Petroleum Engineers, Mexico Section, junio de 1959, p. 3.

${ }^{85}$ URENCIO, "Investigación Tecnológica”, p. 459.

${ }^{86}$ Ignacio Deschamps, "Programa de Investigación Aplicada Actualmente en Operación en el Instituto Mexicano de Investigaciones Tecnológicas”, mimeo, texto presentado ante el American Institute of Mining, Metallurgical \& Petroleum Engineers, Mexico Section, junio de 1959, p. 3.

87 "Reseña del Instituto Mexicano de Investigaciones Tecnológicas", IMIT, ACD, No. 111, 4 de julio de 1975, p. 2. 
Tabla 3

ORGANIZACIÓN DEL IMIT: DIVISIONES EXISTENTENTES

\begin{tabular}{llc}
\hline \multicolumn{1}{c}{1955} & \multicolumn{1}{c}{1959} & 1981 \\
\hline 1) Bibliografía & 1) Investigación & 1) Bibliografía y de Patentes \\
y patentes & Bibliográfica & 2) Investigación Industrial \\
2) Análisis químicos & y de Patentes & a) Unidad de Evaluación y \\
y físicos, & 2) Ingenierías & Desarrollo de Productos \\
3) Pulpa y papel & 3) Química & Industriales \\
4) Carbón y & Analítica & b) Unidad e Bioquímica \\
combustibles & 4) Bioquímica & Industrial \\
5) Productos & Aplicada & c) Unidad de Preingeniería \\
forestales y & 5) Celulosa & de Procesos y Plantas \\
agrícolas & y Papel & Industriales \\
6) Aceites, ceras & 6) Química & 3) Análisis Integral de Proyectos \\
y grasas & Orgánica & Industriales \\
7) Fibras duras & 7) Química & 4) Desarrollo y Estructuración \\
y textiles, & Mineral y & de Proyectos Industriales \\
8) Ingeniería auxiliar & Metalúrgica. & 5) Análisis Sistémico de la \\
9) Promoción & & Estructura Industrial del País \\
industrial & & 6) Capacitación Interna y \\
& & Adiestramiento Especializado \\
& & 7) Programas y Proyectos \\
& & Especiales \\
\hline
\end{tabular}

Fuentes: Deschamps “Programa de Investigación”; IMIT A.C, IMIT A.C.

A partir de 1954, el IMIT inició el Programa de Entrenamiento en Investigación Aplicada, mediante el cual se seleccionaban anualmente alrededor de 25 jóvenes, entre los egresados de las universidades del país, principalmente la UNAM y el Instituto Politécnico Nacional, para realizar su tesis profesional en temas escogidos relacionados con las áreas de los proyectos en operación, que eran supervisadas por los jefes de Investigación del Instituto. Al mismo tiempo, el ImIt les impartía diversos seminarios y cursos especiales para ampliar su conocimiento profesional y se les guiaba por el camino de la investigación formal. Después, aquellos jóvenes que demostraban un 
verdadero interés, ingenio y disciplina, se hacían merecedores de un número limitado de becas para investigación en el propio Instituto por un periodo de uno a dos años. Más adelante, los más selectos eran enviados al extranjero para realizar estudios de posgrado con becas del Banco de México o de diversas entidades internacionales. ${ }^{88}$ Todos los directivos técnicos del IMIT habían recibido entrenamiento adicional en el extranjero en universidades de reconocido prestigio y en centros de investigación de muy diversa índole. ${ }^{89}$

Hacia 1958, este programa de 4 a 5 años de entrenamiento en investigación había permitido dotar al Instituto de un cuerpo técnico total de alrededor de 90 personas. Además, se invitó a varios becarios de países centroamericanos a formar parte del programa, bajo los auspicios de varios gobiernos centroamericanos y con la cooperación de Naciones Unidas. "Por esta vía”, explicaba Deschamps, "varios centenares de jóvenes técnicos de México y de Centro y Sudamérica, vinieron por primera vez aquí a confrontar problemas concretos, de interés económico, cuya solución habría de requerir de esfuerzos sistemáticos y de la aplicación de todo su ingenio y honestidad intelectual, así como de gran perseverancia, como nunca antes en su vida académica previa”.90

${ }^{88}$ Ignacio Deschamps, "Programa de Investigación Aplicada Actualmente en Operación en el Instituto Mexicano de Investigaciones Tecnológicas”, mimeo, texto presentado ante el American Institute of Mining, Metallurgical \& Petroleum Engineers, Mexico Section, junio de 1959, pp. 11-12.

89 Ignacio Deschamps, "Programa de Investigación Aplicada Actualmente en Operación en el Instituto Mexicano de Investigaciones Tecnológicas”, mimeo, texto presentado ante el American Institute of Mining, Metallurgical \& Petroleum Engineers, Mexico Section, junio de 1959, p. 11.

${ }^{90}$ Ignacio Deschamps, "Palabras pronunciadas por el señor Ignacio A. Deschamps Aguilar, en el homenaje que se le dio en el IMIT, con motivo de su retiro como Director General de la institución, en 1982”, Mimeo. 
EL INSTITUTO DE INVESTIGACIONES TECNOLÓGICAS A. C.

En 1960 el IMIT adoptó el régimen de asociación civil con las tres instituciones nacionales de crédito patrocinadoras como asociadas, consiguiendo por medio de esta transformación una mayor independencia. ${ }^{91}$ El Consejo Directivo del Instituto quedó conformado por Plácido García Reynoso y Gonzalo Robles, como representantes del Banco de México, Raúl Martínez Ostos y Alfredo Navarrete, como representantes de Nacional Financiera, y Gonzalo Mora, como representante del Banco Nacional de Comercio Exterior, quien fue sustituido en diciembre de 1965 por Antonio Calderón. ${ }^{92}$ Como delegado del Consejo se designó a Carlos Morett, del Departamento de Investigaciones Industrial del Banco de México, quien fue sustituido un año más tarde por Carlos Quintana, gerente de Programación Industrial de Nafinsa. ${ }^{93}$ En mayo de 1967, Víctor Urquidi ocupó este cargo, al ser Quintana designado secretario ejecutivo de la Comisión Económica para América Latina y el Caribe (CEPAL). ${ }^{94}$

Los consejeros tenían un papel muy activo en el funcionamiento del Instituto, que sesionaba mensualmente, y en ocasiones dos veces por mes. Todo proyecto que emprendiera el IMIT debía contar con su autorización, para lo que analizaban su viabilidad, costos y utilidad para el desarrollo nacional. Una vez aprobados daban seguimiento puntual a los mismos, involucrándose frecuentemente en ampliar sus alcances y conseguir apoyos adicionales. Asimismo, autorizaban el presupuesto anual y estudiaban escrupulosamente los gastos en que incurría el Instituto. Los consejeros autorizaban también las contrataciones y los salarios del personal, así como las becas otorgadas.

91 IMIT, IMIT A.C., Investigaciones, p. 7.

92 IMIT, ACD, No. 1, 5 de abril de 1960, p. 1; IMIT, ACD, No. 83, 14 de diciembre de 1965, p. 1; IMIT, ACD, No. 2, 13 de julio de 1960, pp. 1-2.

93 IMIT, ACD, No. 2, 13 de julio de 1960, pp. 1-2.

94 IMIT, ACD, No. 91, 2 de mayo de 1967, pp. 1-2. 
Los estados financieros del IMIT eran revisados anualmente por una auditoría externa. El alto perfil de los Consejeros, así como la importancia que otorgaban a su función, fue crucial para el desempeño del Iмiт.

El presupuesto anual presentado por el Instituto para 1961 sumaba 7800000 pesos, de los cuales las instituciones asociadas cubrían 4800000 pesos (61\% del total) y el resto se obtenía por medio de los proyectos que realizaba con empresas y otras instituciones. ${ }^{95}$ En general, el IMIT otorgaba un subsidio de $33.33 \%$ a la iniciativa privada en los proyectos o estudios que esta le encomendaba, pero en algunos casos no concedía el subsidio, por considerar que los trabajos que anteriormente había realizado representaban de hecho un subsidio, o bien concedía un subsidio mayor a cambio de un porcentaje de las futuras ventas o regalías. ${ }^{96}$

De acuerdo con una encuesta que realizó la Academia de Investigación Científica en 1964, el IMIT empleaba a 15 investigadores e ingenieros de alto nivel, 25 investigadores adjuntos, 15 técnicos de nivel intermedio, 70 ayudantes de investigación y 20 personas que realizaban funciones administrativas. ${ }^{97}$ "Aunque funciona en escala relativamente limitada”, señalaban Víctor Urquidi y Adrián Lajous en su estudio sobre la investigación científica y tecnológica en México, "el IMIT se destaca por su relación con el desarrollo industrial del país, aun cuando tiene que competir con tecnología importada y con la investigación que realizan en otros países las empresas mexicanas o de capital nacional o extranjero" ${ }^{98}$ Indicaban que su principal problema era carecer de un adecuado financiamiento de base que le permitiera tener un personal científico y técnico más numeroso,

95 IMIT, ACD, No. 11, 14 de diciembre de 1960, p. 2.

${ }^{96}$ IMIT, ACD, No. 4, 5 de septiembre de 1960, p. 3.

97 Urquidi y Lajous, Educación Superior, p. 64 y Espíndola, "Investigación Tecnológica", p. 47.

98 URQuidi y Lajous, Educación Superior, p. 65. 
“y constituyen obstáculos a sus necesidades el ambiente general que prevalece en la industria de transformación mexicana, que no aprecia debidamente la investigación aplicada y con frecuencia descansa casi por completo en tecnología importada, en servicios extranjeros de investigación o en ensayos semitécnicos de insuficiente base científica". ${ }^{99}$ No obstante, valoraban que el IMIT estaba logrando avances en cuanto a la orientación de una política de investigación aplicada.

Diversos proyectos que llevó a cabo el IMIT durante la década de 1960 estuvieron dirigidos a fomentar las exportaciones. Entre ellos destaca la certificación de hilos y telas de algodón de alrededor de 20 fábricas mexicanas para ser exportados a Indonesia. Tarea que le encomendó la Secretaría de Industria a solicitud de la embajada de Indonesia y las empresas textiles. El IMIT cobraba $0.25 \%$ del monto de las exportaciones, lo que cubría apenas la tercera parte del costo de realizarlos, por lo que incluía un subsidio importante. ${ }^{100}$ En 1963 , se calculaba que en los últimos tres años se habían certificado telas e hilos para su exportación que sumaban un total de 305890171.61 pesos. ${ }^{101}$ Además de apoyar la exportación, este proyecto contribuyó a mejoras sustantivas en calidad y costo en las fábricas textiles.

Otro proyecto en esta dirección fue el que buscó el aprovechamiento de maderas tropicales de las selvas chiapanecas en mezclas complejas, que solicitó Maderera Maya, una empresa mixta en la que participó la Vancouver Plywood Co., que condujo a valiosas patentes con características notables para la producción de celulosa al sulfito. Asimismo, se realizaron importantes investigaciones para Fibracel por técnicos del IMIT, con el propósito de incrementar su producción de laminados destinados a la exportación.

99 URquidi y Lajous, Educación Superior, p. 65.

100 IMIT, ACD, No. 12, 11 de enero de 1961, p. 4; IMIT, ACD, No. 16, 27 de febrero de 1961, p. 5.

101 IMIT, ACD, No. 60, 12 de julio de 1963, p. 2. 
El Instituto realizó varios proyectos orientados a la exportación de productos agrícolas, como el que realizó para la industrialización del plátano Tabasco, solicitado por la Unión de Productores de Plátano y por el Bancomext, y el diseño de una planta de fermentación de cacao en Río Seco, Tabasco, gracias a los cuales inició su exportación. ${ }^{102}$ Participó en el desarrollo de un procedimiento para la estabilización de pulpa de aguacate que resultó aplicable también a la de jitomate, que, patrocinado por la empresa Productos de Maíz, y fue contratado por la Asociación Nacional de Productores y Comerciantes de Jitomates y Similares para auxiliarlos en la fabricación de puré de tomate y en el empaque de tomate fresco para el consumo en los mercados nacional y de exportación. ${ }^{103}$ Colaboró también con Cafés de Veracruz, la empresa más importante en México de café tostado, para ampliar su capacidad de producción con el fin de incrementar sus exportaciones de café molido, tostado y envasado al vacío. ${ }^{104}$

Los trabajos del IMIT se orientaron también a proyectos que permitieran sustituir importaciones. Uno de ellos fue su investigación en torno del aprovechamiento del bagazo de caña de azúcar para la producción de papeles diversos, contratado por la Compañía Industrial de San Cristóbal. ${ }^{105}$ Asimismo, realizó varios estudios para sustituir insumos de importación en los alimentos balanceados de pollos para carne y para huevo. ${ }^{106}$ Fueron también significativos los proyectos patrocinados por Química Industrial Nacional, en el renglón de fungicidas derivados del cobre y de otros metales que hasta entonces se

102 IMIT, ACD, No. 4, 5 de septiembre de 1960, p. 5; IMIT, ACD, No. 23, 5 de julio de 1968, pp. 8-9.

103 IMIT, ACD, No. 106, 7 de julio de 1970, pp. 4-6.

104 IMIT, ACD, No. 90, 6 de marzo de 1967, pp. 9-11.

${ }^{105}$ IMIT, ACD, No. 23, 7 de septiembre de 1961, pp. 12-16.

106 IMIT, ACD, No. 6, 20 de septiembre de 1960, pp. 2 y 4; IMIT, ACD, No. 61, 16 de agosto de 1963, pp. 4-7. 
importaban. Realizó asimismo importantes investigaciones relacionadas con la elaboración de alimentos esencialmente de origen vegetal para recién nacidos, capaces de sustituir la leche materna que se importaba. ${ }^{107}$ Como parte de este proyecto, desarrolló el producto Biolacta, con excelente tolerancia por parte de los lactantes y altas cualidades nutritivas, a un costo mucho menor a los sustitutos de leche tradicionales, el cual se produjo en una planta instalada en Guadalajara. ${ }^{108}$

El IMIT continuó colaborando con MINSA, que para entonces dependía de la Compañía Nacional de Subsistencias Populares (Conasupo), para mejorar las propiedades nutritivas y de consistencia de las tortillas de maíz elaboradas con harina. ${ }^{109}$ Entre 1966 y 1967 diseñó la ampliación de la capacidad de producción de la fábrica, para pasar de 60000 a 120000 toneladas anuales; introdujo modificaciones en la materia prima para ampliar su rendimiento y le entregaron seis fórmulas para enriquecer el contenido proteínico de la tortilla mediante aditivos de soya y ajonjolí. ${ }^{110}$

La intervención del IMIT fue crucial en el desarrollo de varias industrias que llegaron a constituirse en algunas de las más exitosas del país. Destaca, entre ellas, la industria cervecera, para la que, desde 1955, realizó proyectos en el área de cebadas y maltas, para producir bebidas de calidad más alta y homogénea. El IMIT mantuvo permanentemente convenios con los industriales malteros que permitieron determinar el comportamiento industrial de distintas cebadas y su capacidad de impartir a la cerveza las

107 Ignacio Deschamps, "Palabras pronunciadas por el señor Ignacio A. Deschamps Aguilar, en el homenaje que se le dio en el IмIт, con motivo de su retiro como Director General de la institución, en 1982", Mimeo; "Breves antecedentes sobre el desarrollo del IMIT que expone el Director General de la Institución”, IMIT, ACD, No. 131, 19 de mayo de 1978, p. 4.

108 IMIT, ACD, No. 75, 9 de noviembre de 1964, pp. 1-3.

109 IMIT, ACD, No. 86, 30 de julio de 1966, pp. 1-2.

110 IMIT, ACD, No. 90, 6 de marzo de 1967, pp. 3-4. 
propiedades que ésta requiere, con el fin de reducir la importación de cebadas malteras. ${ }^{111}$ Se estudiaron cerca de mil variedades de cebadas para seleccionar las que cumplían mejor con las características requeridas para la producción de cerveza, tenían mejor adaptabilidad al suelo mexicano y menores costos. ${ }^{112}$ Asimismo, las empresas cerveceras solicitaron los servicios del IMIT para ajustar las calidades de su cerveza y mejorar sus procesos productivos. En 1981, por ejemplo, la Cervecería Moctezuma lo contrató para revisar todos los sistemas internos de producción a escala industrial. ${ }^{113}$

También fue fundamental la participación del IMIT para la producción de tequila. Hacia 1968, esta industria enfrentaba dificultadas para incrementar su exportación por la falta de materia prima adecuada y debido a que existía "erratismo en gran escala respecto de calidades y marcas". ${ }^{114}$ Gracias a la intervención del IMIT se logró limitar el volumen y los tipos de alcohol que se mezclaban con el mosto tequilero para no distorsionar su sabor, establecer normas de calidad y ampliar la producción de agave. Estos trabajos permitieron aumentar la producción de tequila, y mejorar y uniformar su calidad dentro de cada marca, entre las que estaban Sauza y Cuervo, a fin de impulsar y diversificar sus exportaciones. ${ }^{115}$ También desarrolló investigaciones para Tequila Herradura para el aprovechamiento de productos residuales. ${ }^{116}$

El IMIT colaboró con Celanese Mexicana en diversos proyectos. Uno de ellos comprendió el aprovechamiento en la

111 IMIT, ACD, No. 59, 28 de junio de 1963, pp. 11-13; IMIT, ACD, No. 61, 16 de agosto de 1963 , pp. 7-8.

112 IMIT, ACD, No. 118, 20 de enero de 1977; IMIT, ACD, No. 90, 6 de marzo de 1967, pp. 4-5.

113 IMIT, ACD, No. 16, 7 de octubre de 1981, p. 11.

114 IMIT, ACD, No. 94, 8 de mayo de 1968, p. 10.

115 IMIT, ACD, No. 100, 18 de abril de 1969, p. 10-12.

116 IMIT, ACD, No. 123, 11 de octubre de 1977, p. 10. 
manufactura de papel de los linters de algodón que se producían como desecho. ${ }^{117}$ El IMIT desarrolló también diversos proyectos para la Compañía Adhesivos Resistol entre ellos destaca un proceso para hacer almidón de yuca de alta pureza que la empresa utilizó para distintas aplicaciones industriales en una planta en Chiapas, llegando a vender patentes y procedimientos derivados de este desarrollo a Colombia y Venezuela. En 1965, le ayudó a resolver de manera sistemática problemas que enfrentaba en la producción de triasteín, insumo que en ese momento importaba de Estados Unidos. ${ }^{118}$

Industrias AGA contrató al IMIT para resolver problemas en el uso de nitrógeno líquido, su almacenamiento y la adquisición de equipos. ${ }^{119}$ De igual forma, realizó varios proyectos para Jugos de Frutas Mundet, con el fin de incrementar el uso de frutas naturales en su planta de concentrados. ${ }^{120}$ Frex Port, una empresa del grupo Bimbo, solicitó al IMIT al desarrollo de un proceso de concentración al vacío que condujera a un material estable para ser fabricado durante la época de cosecha de la fresa y usado todo el año para la elaboración de mermelada con fines de exportación. ${ }^{121}$ El IMIT colaboró asimismo con la Compañía Hulera Euzkadi, la Compañía Minera Autlán, la compañía procesadora de frutos y legumbres Herdez y muchas otras grandes empresas. ${ }^{122}$

Los servicios del IMIT se dirigieron también al desarrollo de la pequeña industria. A instancias del Banco Nacional de Fomento Cooperativo, en 1970 emprendió un proyecto para apoyar a la industria artesanal de objetos de alfarería y cerámica, con el fin

117 IMIT, ACD, No. 95, 12 de junio de 1968, pp. 11-12.

118 IMIT, ACD, No. 81, 20 de agosto de 1965, p. 8.

119 IMIT, ACD, No. 108, 28 de noviembre de 1970, p. 4.

${ }_{120}$ IMIT, ACD, No. 109, 6 de junio de 1974, p. 9; IMIT, ACD, No. 118, 20 de enero de 1977, pp. 3-4.

121 IMIT, ACD, No. 123, 11 de octubre de 1977, pp. 7-8.

122 IMIT A.C, IMIT, p. 16. 
de limitar sus niveles de plomo y reducir la merma que sufrían en elevados porcentajes al romperse al entrar en el horno. El IMIT desarrolló una resina sintética para agregar a la arcilla antes de moldearla y aumentar su resistencia. ${ }^{123}$ Estos proyectos beneficiaron a los productores de Guanajuato, Metepec y Valle de Bravo, permitiéndoles exportar. ${ }^{124}$ Otros proyectos buscaron generar elementos de juicio para orientar mejor la operación de créditos que promovían instituciones públicas a través de la banca privada. Uno de ellos fue el estudio comparativo de la eficiencia e implicaciones en rentabilidad de 18 alimentos balanceados para aves ponedoras, que les solicitó el Fondo de Garantía y Fomento para la Agricultura, Ganadería y Avicultura. ${ }^{125}$

Durante esta segunda etapa, el Instituto fue incorporando entre sus actividades la ingeniería de procesos y consolidó un equipo técnico y un cuerpo especializado en los aspectos económicos para encarar de manera formal los problemas del análisis y evaluación de los proyectos a escala industrial. También conformó la Unidad de Pre-Ingeniería para analizar los sistemas, equipos y otros requerimientos en la implementación de los proyectos. ${ }^{126} \mathrm{El}$ IMIT contaba ya con amplias instalaciones de operaciones unitarias, de aplicación múltiple. ${ }^{127}$

La estructura interna del IMIT se reorganizó en función de tres divisiones fundamentales: la de Procesos y Productos Industriales, que realizaba investigación estrictamente aplicada con recursos apropiados del laboratorio y a escala piloto; la de Ingeniería y Desarrollo, que encaraba la adecuación de procesos y equipos de los proyectos de la industria, y la de Estudios Técnico-Económicos, que procuraba un equilibrio apropiado de las variables de influencia económica y sugería el tratamiento

\footnotetext{
${ }^{123}$ IMIT, ACD, No. 105, 15 de abril de 1970, pp. 4-6.

${ }^{124}$ IMIT, ACD, No. 105, 7 de julio de 1970, pp. 7-10.

125 IMIT, ACD, No. 6, 20 de septiembre de 1960, pp. 14.

126 IMIT, ACD, No. 118, 22 de agosto de 1969, pp. 13.

127 IMIT A.C., IMIT, pp. 7 y 13.
} 
financiero más apropiado. Las tres divisiones trabajaban en forma conjunta e interdisciplinaria. ${ }^{28}$ Esto le permitía al IMIT "analizar los problemas en un contexto integral y tomar en cuenta el efecto conjugado y la interdependencia funcional de las cuestiones técnicas y económicas que caracterizan el fenómeno industrial". 129

\section{EL IMIT Y EL SECTOR FINANCIERO}

Mientras que hasta 1974 hubo gran estabilidad en los miembros del Consejo Directivo del IMIT, este cambió sustancialmente en ese año, quedando conformado por Ernesto Fernández Hurtado y Gonzalo Robles como representantes del Banco de México, Gustavo Romero Kolbeck y Carlos Quintana como representantes de Nafinsa, y Francisco Alcalá y José Bravo Silva como representante del Bancomext. El único que había formado parte de los consejos anteriores era Gonzalo Robles. Asimismo, se eliminó el puesto de delegado del Consejo, si bien decidieron conservar los servicios de Víctor Urquidi, en calidad de asesor de la Dirección del Imiт. 130

Los nuevos consejeros resaltaron la importancia de las labores que realizaba el IMIT en el área de pre-inversión, "dada su significación en la mejor utilización de los recursos financieros de que dispone el país”, y solicitaron al IмIт que procurara estar "en íntimo contacto con la canalización de los recursos de apoyo y crédito a la industria", actividad que preveían sería "de significado creciente y de efectos inmediatos y provechosos para la economía del país". ${ }^{131}$ Así, el IMIT entró en una tercera

128 "Reseña del Instituto Mexicano de Investigaciones Tecnológicas”, IMIT, ACD, No. 111, 4 de julio de 1975, p. 5.

129 "Reseña del Instituto Mexicano de Investigaciones Tecnológicas”, IMIT, ACD, No. 111, 4 de julio de 1975, p. 6.

130 IMIT, Asamblea Extraordinaria, 28 de febrero de 1974, pp. 1-2.

131 IMIT, Asamblea Extraordinaria, 28 de febrero de 1974, p. 5. 
etapa, en la que "expandió sus estudios más allá de las metas meramente tecnológicas” para incluir las cuestiones "relativas al análisis y estructuración económica y financiera de proyectos industriales". ${ }^{132} \mathrm{Su}$ vinculación al sector financiero lo hacía un organismo idóneo y confiable en materia de asesoría para las industrias solicitantes, para la justificación y otorgamiento de crédito por parte de las instituciones financieras. ${ }^{133}$

Ya por encomienda de las instituciones de crédito o por gestión directa de las industrias, sus trabajos se enfocaron en la evaluación integral de nuevos proyectos en el periodo previo al diseño y erección de las plantas industriales. Cuando resultaban viables, el IMIT contribuía a fortalecerlos a partir de recomendaciones técnicas y financieras, pero aconsejaba "frenar e inclusive a impedir el desarrollo de los que exhibían una escala o nula fundamentación”. ${ }^{134}$ De acuerdo con Fernández Hurtado, esta labor generaba importantes ahorros, comentando que existía "un ejemplo evidente en la mejoría de proyectos, en uno de los cuales la intervención del IMIT evitó un gasto de más de \$100 millones de pesos”. ${ }^{135} \mathrm{El}$ creciente número de proyectos de evaluación y preingeniería fue promovido por la organización en el sistema financiero de mecanismos especializados de redescuento, que permitían que una parte de los créditos otorgados se destinaran a estudios de preinversión. ${ }^{136}$

Entre 1973 y 1975, el IMIT analizó 117 proyectos, de los cuales, 31 fueron descartados en una primera instancia por acusar escasa fundamentación. De los 86 restantes, llegaron a su

\footnotetext{
132 “Breves antecedentes”, IMIT, ACD, No. 131, 19 de mayo de 1978, p. 4.

133 Rivera, “Administración pública y desarrollo industrial”, p. 22.

134 “Reseña del Instituto Mexicano de Investigaciones Tecnológicas”, IMIT, ACD, No. 111, 4 de julio de 1975, p. 6.

135 IMIT, Asamblea Extraordinaria, 28 de febrero de 1974, p. 15.

136 Ignacio Deschamps, "Palabras pronunciadas por el señor Ignacio A. Deschamps Aguilar, en el homenaje que se le dio en el IMIT, con motivo de su retiro como Director General de la institución, en 1982”, mimeo.
} 
culminación $80 \%$. Alrededor de un tercio de ellos requirieron de una reestructuración amplia en lo económico y financiero, sin haber incurrido en reformas de orden técnico. Un $10 \%$ fueron reformados sustancialmente por medio de esfuerzos de ingeniería. Un $15 \%$ se optimizaron mediante el rediseño de su mosaico productivo y, en algunos casos, mediante ampliaciones en los volúmenes de producción y cierto grado de diversificación. Un $12 \%$ exhibió mejoras económicas sustanciales mediante cambios en las materias primas, y $15 \%$ de los proyectos se beneficiaron mediante el incremento de la capacidad y la introducción de cambios en la estructura financiera. Si bien sólo $8 \%$ de los mismos dieron lugar a esfuerzos de investigación tecnológica, muchas de las oportunidades y coyunturas aprovechadas se realizaron en el marco de una actitud clara de investigación aplicada, sin la cual no habrían podido detectarse. ${ }^{137}$

Entre los proyectos en los que el IMIT intervino de forma integral estuvo el de Industrial Texmelucan, cuyo estudio de preingeniería sirvió de base para el diseño y construcción de una nueva planta para fabricar 105000 toneladas anuales de productos cerámicos con una inversión del orden de 130 millones de pesos, patrocinado por el Consejo de Administración de Cerámica Santa Julia. Otro caso en el que el IMIT contribuyó con un estudio integral fue el que realizó Molinos Unión del Yaqui en Sonora con el fin de iniciar el procesamiento de oleaginosas de soya y cártamo en la región de Ciudad Obregón, que significó una inversión de alrededor de 80 millones de pesos. Gracias a la planeación técnica cuidadosa se logró una eficiencia en la extracción de disolventes similar a las mejores de su género a nivel internacional. Otro ejemplo destacable fue la intervención del IмIт en la planeación técnica y económica de la construcción de una nueva planta en Montemorelos para la producción

137 “Reseña del Instituto Mexicano de Investigaciones Tecnológicas”, IMIT, ACD, No. 111, 4 de julio de 1975, pp. 10-12. 
de derivados cítricos. Su éxito les permitió a los citricultores de Nuevo León iniciar su exportación a Japón. ${ }^{138}$

En 1976 el IMIT realizó 72 evaluaciones técnico-económicas y financieras de proyectos industriales con fines de crédito, que sumaban inversiones por 6982.5 millones de pesos. Estas le fueron encomendadas por diversas instituciones públicas como Nafinsa, el Banco de México, el Fondo de Equipamiento Industrial y el Fondo de Garantía para la Agricultura, pero también por muchas privadas como el Banco Internacional, el Banco Nacional de México, el Banco del Atlántico, el Banco Minero y Mercantil, el Banco del Noroeste de México y el Banco de Londres y México, entre otras. Una de ellas fue encomendada por el Bank of America, United California Bank, Wells Fargo Bank, Bank of Montreal y Citibank, quienes le solicitaron un estudio para evaluar un crédito para Kimex con el fin de construir una planta de policondensación para producir chip de poliéster. ${ }^{139} \mathrm{El}$ costo unitario del servicio que cobró el IMIT fue de entre 100000 y 1800000 pesos, dependiendo de su monto y complejidad. ${ }^{140}$ Al mismo tiempo el IMIT seguía llevando a cabo proyectos.

Durante los siguientes años se dieron constantes cambios en los miembros del Consejo, lo que contrasta con el periodo previo. En enero de 1977, los representantes del Banco de México eran Gustavo Romero Kolbeck y Jorge Espinosa de los Reyes, quien fue designado consejero alterno debido a la precaria salud de Gonzalo Robles. Los representantes de Nafinsa eran David Ibarra Muñoz y Luis Almeida Durán, y los del Bancomext eran

138 "Discurso de Ignacio Deschamps en ocasión del vigésimo quinto aniversario de la fundación del Instituto Mexicano de Investigaciones Tecnológicas A.C.”, IMIT, ACD, No. 111, 4 de julio de 1975, pp. 9-10.

139 IMIT, Carta de Paolo Melloni, gerente auxiliar de Citibank, a Ignacio Deschamps, director general del IмIт, 29 de septiembre de 1976.

140 IMIT, Asamblea de las Instituciones Asociadas, febrero 1, 1977. Anexo 2. "Evaluación Técnico-económica y Financiera de Proyectos Industriales con Fines de Crédito". 
Francisco Alcalá Quintero y José Bravo Silva. ${ }^{141}$ En 1981 Luis Sánchez Lugo se sumó a los representantes del Banco de México, Adrián Lajous fungía como representante del Bancomext y Cristóbal Lara Beautell era representante de Nafinsa. ${ }^{142}$

En 1977 el Consejo vio con preocupación que se ubicara al IMIT en el sector correspondiente a la Secretaría del Patrimonio y Fomento Industrial. ${ }^{143}$ Inmediatamente, Gustavo Kolbeck dirigió una carta a Rodolfo Moctezuma Cid, entonces secretario de Hacienda y Crédito Público, para solicitarle que se reubicara al Instituto dentro del sector que dirigía, lo que se consiguió a los pocos meses. ${ }^{144}$ Poco después el IMIT ajustó su objeto social para fundamentar su reubicación en la Secretaría de Hacienda. A partir de entonces el Instituto adoptó el nombre de IмIт A. C., al que agregó la leyenda "Instituto de Apoyo Técnico para el Financiamiento de la Industria". ${ }^{145}$ A partir de mayo de 1978 se incluyeron en el Consejo Directivo representantes de la Secretaría de Patrimonio y Fomento Industrial, de la Asociación de Banqueros de México A. C. y de la Confederación de Cámaras Industriales. ${ }^{146}$

Hacia 1981 la organización del IMIT había cambiado sustantivamente con relación a su estructura de la década de 1950, reflejando el grado de sofisticación que había alcanzado el instituto en la investigación y desarrollo de proyectos industriales y en la capacitación y adiestramiento de técnicos (véase la tabla 3).

El IMIT continuó consolidándose en términos de la formación de capital humano. Anualmente el IMIT adiestraba a un grupo de

${ }^{141}$ IMIT, ACD, No. 111, 4 de julio de 1975, p. 1; IMIT, ACD, No. 118, 20 de enero de 1977, p. 1.

142 IMIT, ACD, No. 166, 17 de agosto de 1981, p. 1.

143 IMIT, Asamblea de las Instituciones Asociadas, 1 de febrero de 1977.

144 IMIT, Carta de Gustavo Romero Kolbeck, director general del Banco de México al Lic. Rodolfo Moctezuma Cid, secretario de Hacienda y Crédito Público, 3 de febrero de 1977.

145 IMIT, ACD, No. 119, 5 de julio de 1977, pp. 3-5.

146 IMIT, ACD, No. 131, 19 de mayo de 1978, pp. 1-2. 
entre 50 y 60 jóvenes en técnicas de investigación industrial relacionada con el desarrollo de proyectos integrales cubriendo aspectos de análisis y estructuración. ${ }^{147}$ En 1975, se estimaba que cerca de 2000 técnicos en diversas disciplinas habían sido entrenados por el IмIт. ${ }^{148}$ Asimismo el IMIT comenzó a ofrecer adiestramiento externo a entidades de redescuento y del sistema bancario en general, por medio de la organización de mesas de intercambio dirigidas al personal de instituciones bancarias, los fondos de inversión y la Secretaría de Hacienda. También se organizaron cursos especializados para extensionistas de Nafinsa pertenecientes al Programa Integral de Apoyo a la Pequeña y Mediana Industria. ${ }^{149}$

En 1979, los ingresos anuales del IMIT fueron de 34.6 millones de pesos, de los cuales 17.8 millones fueron aportados por el Banco de México, Nafinsa y Bancomext, más 2.3 millones otorgados por el Banco de México para becas. Asimismo el IMIT ingresó 14.5 millones de pesos por servicios remunerados, que representaban $42 \%$ del total de sus ingresos. ${ }^{150}$ En ese año se planteó la posibilidad de que se constituyera un fondo financiero por parte de las instituciones asociadas y la Secretaría de Hacienda, que administrara el Banco de México con el fin de transmitir al IMIT sus rendimientos financieros para ampliar sus programas. ${ }^{151}$

En 1980 Miguel de la Madrid, secretario de Programación y Presupuesto, informó que se entregaría al Banco de México, a favor del IMIT un fondo de apoyo complementario por $450 \mathrm{mi}-$ llones de pesos, en tres anualidades a partir de 1980. El Banco de México manejaría dicho fondo entregando los rendimientos al

147 IMIT A.C., IMIT, p. 15.

148 "Reseña del Instituto Mexicano de Investigaciones Tecnológicas", IMIT, ACD, No. 111, 4 de julio de 1975, p. 2.

149 IMIT, ACD, No. 140, 22 de marzo de 1979, p. 5.

150 IMIT, ACD, No. 145, 18 de octubre de 1979, pp. 3 y 6.

151 IMIT, ACD, No. 146, 18 de diciembre de 1979, pp. 14-15. 
IMIT. Originalmente se consideró que las instituciones asociadas aportarían al fondo 275 millones de pesos, pero esto no se llevó a cabo, por lo que se elaboró un convenio con la Secretaría de Hacienda mediante el cual se condicionó que la suma que se otorgara al Instituto por el rendimiento del fondo fuera a razón de dos pesos por cada peso que aportaran en su conjunto las instituciones propietarias. En 1981, el Banco de México, Nafinsa y Bancomext aportaron 28044000 pesos, por lo que se pudieron utilizar 56088000 del rendimientos del fondo; el resto se fue acumulando en el mismo. ${ }^{152}$

Hacia 1981 el IMIT mostraba una lista de más de 200 empresas industriales para las que había elaborado algún proyecto, entre las que se encontraban las más importantes del país. ${ }^{153}$ Muchos sectores industriales que al cabo de los años han seguido prosperando en México, como las industrias cervecera, tequilera, de harina de maíz y de cerámicas, lograron consolidar sus mercados de exportación gracias al apoyo tecnológico que les brindó el IMIT.

\section{EL DECLIVE Y CIERRE DEL IMIT}

La crisis económica que sacudió al país en 1982 significó importantes problemas para el Instituto. Le tocó al ingeniero Juan Manuel Lomelín dirigir el instituto durante esos años difíciles en los que el instituto continuó en actividad a pesar de las severas limitaciones que impuso la crisis. No sólo las instituciones gubernamentales que apoyaban al IMIT vieron reducidos sus recursos, sino que la disminución de la inversión privada también limitó los ingresos del Instituto. La estatización de la banca que decretó el entonces presidente de México, José López Portillo, el 1o de septiembre de ese año, significó un duro golpe para el

152 IMIT, ACD, No. 154, 5 de septiembre de 1980, pp. 7-8; No. 155, 9 de octubre de 1980, 9-14; No. 156, 8 de diciembre de 1980, pp. 2-6; IMIT, ACD, No. 171, 17 de diciembre de 1981, pp. 5-7.

153 IMIT A.C, IMIT, p. 16. 
Instituto, pues la banca, una vez estatizada, dejó de considerar relevante realizar estudios de evaluación técnico-económicos para financiar los proyectos que solicitaban su crédito. Además, las evaluaciones que fueron encomendadas al IмIт dejaron de ser tomadas en cuenta, obedeciendo el flujo de los créditos a razones más de carácter político. Ignacio Deschamps aseguraba que, si se estudiaran los expedientes de las empresas que se fueron a la quiebra durante la crisis de 1995 y tuvieron que ser rescatadas por el Fondo Bancario de Protección al Ahorro (Fobaproa), se encontraría que dichos créditos no contaban con una evaluación del IMIT, y que cuando ésta se realizó el IMIT emitió una recomendación negativa a su otorgamiento. ${ }^{154}$ Esto implicó para el IMIT un flujo mucho menor de recursos provenientes del sector bancario. Sin embargo, el fondo que se constituyó en 1980 le permitió al IMIT continuar funcionando, aportando servicios a la industria.

A partir de mediados de la década de 1980, ante las políticas de mayor apertura y "modernización" económicas impulsadas por el gobierno, se concebía al IMIT como una institución clave para apoyar a la industria nacional "a competir con las importaciones extranjeras para lograr una mejor y más amplia competitividad". ${ }^{155}$ Durante esos años, el IMIT, por ejemplo, apoyó a una empresa del Grupo Industrial Progar, dedicada a la fabricación de productos para la limpieza doméstica, con un análisis de mercado, asesoría para la adquisición de maquinaria de tecnología avanzada, y la organización de sus procesos productivos. La empresa recibió un crédito de Nafin y la banca comercial que le permitió iniciar sus operaciones en 1991, compitiendo exitosamente con Procter and Gamble, ColgatePalmolive y Química Allen, y en 1994 comenzó a exportar a

154 Entrevista con Jaime Deschamps, 5 de octubre de 2018.

155 Rivera, “Administración pública y desarrollo industrial”, p. 38. 
Centro y Sudamérica. ${ }^{156}$ Se consideraba que las aportaciones del IMIT "respecto al desarrollo y puesta en marcha de programas de investigación tecnológica para la industria" serían todavía más valiosas, "ya que gracias al TLC, América del Norte (México, Canadá y Estados Unidos) podrá producir más barato, con mejor calidad y vender en todo el mundo". ${ }^{157}$

Desafortunadamente, el papel estratégico que podía desempeñar el IMIT ante el nuevo entorno económico de mayor apertura no fue valorado por los funcionarios que llegaron al gobierno durante esa década. De acuerdo con la nueva visión imperante, de corte neoliberal, el Banco de México debía enfocarse exclusivamente al combate a la inflación y a dejar de emprender otro tipo de tareas. Con este fin en 1993 se emprendieron importantes reformas constitucionales y en diciembre de ese año se promulgó una nueva Ley del Banco de México, que si bien le otorga al banco central la ansiada autonomía, también limitaba sus atribuciones sólo al combate a la inflación. ${ }^{158} \mathrm{~A}$ raíz de estas reformas, al poco tiempo se eliminó el Departamento de Investigaciones Industriales de la estructura del banco. $\mathrm{Al}$ año siguiente el гміт fue clausurado por Francisco Gil Díaz, quien entonces presidía el Banco de México.

Las instalaciones del IMIT fueron adjudicadas al Politécnico Nacional, que estableció en ellas en 1996 el Centro de Investigación en Ciencia Aplicada y Tecnología Aplicada (CICATA), pero el personal del IмIT fue despedido, perdiéndose el aprendizaje institucional y técnico que se había construido a lo largo de décadas. Ignacio Deschamps relataba que a sólo dos años de haberse cerrado el IMIT intentó realizar algunos experimentos en sus laboratorios y con gran desazón se dio cuenta de que era imposible hacerlo pues gran parte de los mismos había sido

156 RiverA, “Administración pública y desarrollo industrial”, p. 39.

157 RiverA, “Administración pública y desarrollo industrial”, p. 47.

158 Turrent, Autonomía, pp. 183-189. 
desmantelada y el resto había sido dejada al abandono y ya no funcionaba. ${ }^{159}$ Los resultados del CICATA a lo largo de estas últimas décadas han sido muy limitados. La necesidad de confidencialidad que requieren los proyectos de la naturaleza que emprendía el IMIT hace muy difícil que estos puedan llevarse a cabo en instituciones de carácter universitario. Además, su falta de vinculación con el sector financiero y empresarial ha hecho que sus investigaciones tengan muy poco impacto real. Hoy día el personal del CICATA, no sabe que sus instalaciones pertenecieron algún día al IMIT; ni siquiera saben qué era el IMIT.

\section{CONCLUSIONES}

El estudio del nacimiento y la trayectoria del IMIT sugieren que "el milagro mexicano" se explica en gran medida por el éxito de las políticas que se enfocaron adecuadamente a aumentar las capacidades tecnológicas del país a fin de aprovechar sus recursos naturales y aumentar la competitividad de su industria. Estas fueron el resultado de esfuerzos visionarios de varios ingenieros, economistas y científicos mexicanos y estadounidenses que supo aglutinar el Banco de México en un proyecto de cooperación de largas miras, con la Armour Research Foundation.

El establecimiento y desarrollo del IMIT permitió hacer frente a fallas de mercado que impedían el desarrollo tecnológico en México. Sus laboratorios, plantas piloto y personal capacitado resolvían el problema de economías de escala que impide que las empresas cuenten con servicios de esta naturaleza en sus propias instalaciones.

Además, el Iмiт permitió canalizar recursos públicos de forma eficiente para resolver fallas de información y de mercados incompletos que impedían desarrollar personal técnico vinculado a la industria y tecnologías que resolvieran los

159 Entrevista con Jaime Deschamps, 5 de octubre de 2018. 
problemas específicos que enfrentaba el país para explotar sus recursos naturales generando mayor valor agregado. Debido a que estos problemas no eran los que enfrentaban otros países, resultaba imposible que dichos desarrollos tecnológicos fueran elaborados en el extranjero. Un interesante ejemplo de ello es el desarrollo de la harina de maíz nixtamalizado para la producción de tortillas, el principal alimento de los mexicanos. En este rubro entran también las diversas adecuaciones tecnológicas que realizó el IMIT para adaptar la tecnología existente al uso de los recursos naturales específicos del país.

La vinculación directa del IMIT con las principales instituciones financieras públicas con las que contaba el país le permitió tener gran influencia en las decisiones de crédito y dirigir las inversiones a los proyectos industriales que prometían mayor rentabilidad e impacto en el desarrollo nacional. Su vinculación con la iniciativa privada, tanto industrial como bancaria, fue estrecha lo que generó altos grados de eficiencia en el uso de los recursos del instituto, y le otorgó una gran incidencia práctica a sus investigaciones.

Un examen de las características del sistema científico y tecnológico de México señalaba que uno de sus principales problemas era que los centros o institutos de ciencia y tecnología "están desvinculados del aparato económico en lo que concierne a la investigación"160 y sus esfuerzos se orientaban "hacia una actividad con poca relación con la producción”. ${ }^{161}$ El IMIT era una notable excepción, reuniendo muchos de los atributos que se consideran deseables en la política de apoyo al desarrollo científico y tecnológico que actualmente se persiguen en el país por instituciones como el Consejo Nacional de Ciencia y Tecnología (Conacyt) y que parecen imposibles de alcanzar. El entramado

160 Chávez, de la Vega y NadAl, “Características del sistema científico y tecnológico”, p. 270.

161 Chávez, de la Vega y Nadal, “Características del sistema científico y tecnológico”, p. 271. 
institucional y las capacidades técnicas que había logrado adquirir el IMIT habían tomado muchos años en construirse y no eran fácilmente reproducibles. Desafortunadamente, los problemas económicos y errores de política que llevaron al país a la crisis y la estatización de la banca destruyeron el equilibrio y desarticularon el marco institucional que permitió florecer al IMIT. Desafortunadamente también, los economistas que llegaron al poder en la década de 1990, cegados por una excesiva confianza en las fuerzas del mercado, no pudieron aquilatar el valor que una institución como el IMIT podía aportar al desarrollo industrial orientado hacia las exportaciones que anhelaban alcanzar. Fue así que desapareció el IMIT.

\section{SIGLAS Y REFERENCIAS}

AGN Archivo General de la Nación, Ciudad de México, México.

IMIT Instituto Mexicano de Investigaciones Tecnológicas (Archivo privado de la familia Deschamps), México.

IMIT, ACD Instituto Mexicano de Investigaciones Tecnológicas, Actas de Consejo, México.

Armour Research Foundation, Technological and Economic survey of Argentine Industries with Industrial Research Recommendations", Ann Arbor, Michigan, Edwards Brothers Inc., Armour Research Foundation, 1947.

Armour Research Foundation of Illinois Institute of Technology, Proceedings of the Mexican-American Conference of Industrial Research, September 30-October 6, Chicago, Armour Research Foundation of Illinois Institute of Technology, 1945.

Armour Research Foundation, Technological Audit of Selected Mexican Industries with Industrial Research Recommendations, Project 1-265, Ann Arbor, Michigan, Edwards Brothers Inc., 1946.

Armour Research Foundation, Technological and Economic Survey of Argentine Industries with Industrial Research Recommendations, Project 1-143, Ann Arbor, Michigan, Edwards Brothers Inc., 1947. 
Armour Research Foundation, "Direction of the Laboratories of the Instituto Mexicano de Investigaciones Tecnológicas, Final Report for Banco de México S.A.”, Project No. I 517, 3 de noviembre de 1954.

Armour Research Foundation, "Preliminary technological audit for the industrial development of El Salvador", Chicago, International Division Armour Research Foundation of the Illinois Institute of Technology, Project No. 1-804-I, 16 de mayo de 1950.

Ayala Ramírez, Jaime, “The Colombian Institute for Technological Research at Bogotá”, UNIDO, DO3946, 1970, pp. 12-16.

Campos Salas, Octaviano, "Las instituciones nacionales de crédito", en México: Cincuenta años de revolución. I. La economía, México, Fondo de Cultura Económica,1960, pp. 414-444.

CÁrdenas, Enrique, La política económica en México, 1950-1994, México, El Colegio de México, Fondo de Cultura Económica, 1996.

CÁrdenas, Enrique, "La economía mexicana en el dilatado siglo xx, 19292009”, en KunTz (coord.), 2010, pp. 503-548.

Chávez, Fernando, Ángel de la Vega y Alejandro Nadal, "Características del sistema científico y tecnológico de México", en Demografía y Economía, vIII: 3 (1974), pp. 269-306.

EsPíndola Flores, Silvano, “Investigación tecnológica, importación de tecnología y desarrollo económico: el caso de México", tesis de licenciatura en economía, México, Instituto Tecnológico Autónomo de México, 1969.

Gauss, Susan M., Made in Mexico. Regions, Nation, and the State in the Rise of Mexican Industrialism, 1920s-1940s, University Park, Pennsylvania, The Pennsylvania State University Press, 2010.

Gerschenkron, Alexander, Economic backwardness in historical perspective: a book of essays, Cambridge, Mass., Harvard University, 1962.

González y González, Luis, Historia de la Revolución Mexicana, 19341940, México, El Colegio de México, 1979.

Griffin, Keith B., Economía politica del cambio agrario: un ensayo sobre la Revolución Verde, México, Fondo de Cultura Económica, 1982. 
IMIT IMIT A.C., Investigaciones y asesoría al servicio de la industria y el sistema bancario del país, México, Comunicación y Diseño A. P, 1981.

JoHnson, Chalmers, MITI and the Japanese Miracle. The Growth of Industrial Policy, 1925-1975, Stanford, Calif., Stanford University Press, 1982.

Kuntz, Sandra (coord.), Historia económica general de México. De la Colonia a nuestros días, México, El Colegio de México, Secretaría de Economía, 2010.

Moreno-Brid, Juan Carlos y Jaime Ros Bosch, Desarrollo y crecimiento en la economía mexicana. Una perspectiva histórica, México, Fondo de Cultura Económica, 2010.

Mrren, Delbert T., "The Rockefeller Foundation Program in Corn and Wheat in Mexico. Case Study", en Wharton, 1969, pp. 438-452.

Окімото, Daniel I., Between MITI and the Market. Japanese Industrial Policy for High Technology, Stanford, Calif., Stanford University Press, 1989.

Pack, Howard y Larry E. WestPhal, "Industrial strategy and technological change: Theory versus reality", en Journal of Development Economics, 22: 1 (jun. 1986), pp. 87-128.

Rand, Myron J. (comp.), Industrial Research Laboratories of the United States, Washington D. C., National Research Council y National Academy of Sciences, 1950.

Reynolds, Clark, “Por qué el 'desarrollo estabilizador' de México fue en realidad desestabilizador”, en El Trimestre Económico, 11: 176 (oct.-dic. 1977), pp. 997-1023.

Rivera Romay, Óscar José, “Administración pública y desarrollo industrial en México. Estudio de caso, el Instituto Mexicano de Investigación Tecnológica IMIT A. C. 1950-1994", tesina de licenciatura en ciencias políticas y administración pública, Universidad Nacional Autónoma de México, 1995.

Robles, Gonzalo, "El desarrollo industrial”, en México. Cincuenta años de revolución. I. La economía, México, Fondo de Cultura Económica,1960, pp. 166-535.

Rougier, Marcelo y Juan Odisio, "Argentina será industrial o no cumplirá sus destinos." Las ideas sobre el desarrollo nacional (1914-1980), Buenos Aires, Imago Mundi, 2017. 
Romero Sotelo, María Eugenia, "Rodrigo Gómez: una banca central para el desarrollo", en Economía UNAM, 11: 31 (nov. 2014), pp. 53-83.

SoLís, Leopoldo, La realidad económica mexicana: retrovisión y perspectivas, México, Siglo Veintiuno Editores, 1993.

Sonnenfeld, David A., “Mexico’s ‘Green Revolution,' 1940-1980: Towards an Environmental History”, en Environmental History Review, 16: 4 (1992), pp. 28-52.

Turrent, Eduardo, Banco de México. Su historia en cápsulas, México, Banco de México, 2008.

Turrent, Eduardo, Autonomía de la Banca Central en México. Visión histórica, México, Banco de México, 2012.

URencio R., Fausto, “Investigación Tecnológica en México”, en Comercio Exterior (nov. 1955), pp. 458-459.

URQuidi, L. Víctor y Adrián Lajous VARgas, Educación Superior, ciencia y tecnología en el desarrollo económico de México. Un estudio preliminar, México, El Colegio de México, 1967.

Viotтi, Eduardo B, “National Learning Systems: A new approach on technological change in late industrializing economics and evidence from the cases of Brazil and South Korea", en Technological Forecasting and Social Change, 69: 7 (sep. 2002), pp. 653-680.

WANG, Jenn-Hwan, "From technological catch-up to innovation-based economic growth: South Korea and Taiwan compared", en The Journal of Development Studies, 43: 5 (2007), pp. 1084-1104.

Weidlein, Edward R., “The Organization, Management, and Effectiveness of Institutional Research" en Armour Research Foundation, Proceedings, pp. 25-37.

Wharton JR., Clifton R. (ed.), Subsistence Agriculture and Development, Chicago, Aldine Publishing Co., 1969.

Young, L. Norton, "El Instituto de Investigaciones Tecnológicas (IIT) (Institute for Technological Research, Bogotá, Colombia”), UNIDO DO 1674, 1967, pp. 55-56. 
